\title{
Facilitating Dialogue through Design to Create Positive Social Change in Rural Communities
}

\author{
Lauren B. Schiefelbein
}

Follow this and additional works at: https://researchrepository.wvu.edu/etd

\section{Recommended Citation}

Schiefelbein, Lauren B., "Facilitating Dialogue through Design to Create Positive Social Change in Rural Communities" (2015). Graduate Theses, Dissertations, and Problem Reports. 6581.

https://researchrepository.wvu.edu/etd/6581

This Thesis is protected by copyright and/or related rights. It has been brought to you by the The Research Repository @ WVU with permission from the rights-holder(s). You are free to use this Thesis in any way that is permitted by the copyright and related rights legislation that applies to your use. For other uses you must obtain permission from the rights-holder(s) directly, unless additional rights are indicated by a Creative Commons license in the record and/ or on the work itself. This Thesis has been accepted for inclusion in WVU Graduate Theses, Dissertations, and Problem Reports collection by an authorized administrator of The Research Repository @ WVU. For more information, please contact researchrepository@mail.wvu.edu. 


\title{
Facilitating Dialogue through Design to Create Positive Social Change in Rural Communities
}

\author{
Lauren B. Schiefelbein \\ Thesis submitted to the \\ College of Creative Arts \\ West Virginia University \\ In partial fulfillment of the \\ requirements for \\ the degree of \\ Master of Fine Arts \\ In \\ Art \& Design \\ Eve Faulkes, M.F.A. Chair \\ Joseph Galbreath, M.F.A. \\ Kofi Opoku, M.F.A. \\ Michael Sherwin, M.F.A. \\ College of Creative Arts \\ Morgantown, West Virginia \\ 2015
}

Keywords: Social Impact Design, Design Thinking, Audience Segmentation, Rural Communities, Facilitating Dialogue

Copyright 2015 Lauren Schiefelbein 


\section{Abstract}

Social Design is a progressive field that continues to gain momentum across the nation and the world. Its value and validity is especially noteworthy when design is used as a vehicle to create positive change in today's society. Many rural communities lack the necessary infrastructures or resources to remain relevant in a 21 st century world, and face unique sets of barriers to progress and creative problem-solving.

Effective communication, for example, is one area that design thinking can efficiently address, often generating collaborative solutions. Facilitating dialogue in the rural community requires special attention and planning. A carefully-tailored strategy of design interaction while communicating a message of positive change has great potential for allowing more open dialogue, greater levels of support and increased advocacy surrounding any local issue, challenge, or problem within such demographic populations. Properly applied design thinking has the power to act as a major catalyst in empowering smaller communities to find smart, sustainable solutions in building better, brighter futures for its citizens.

My thesis research was applied to a case study involving the efforts of the Friends of George Byrer Field (FOGBF), a grassroots organization searching for solutions to bring a stateof-the-art performance, athletic and fitness facility to Barbour County, West Virginia. Located in rural Appalachia, Barbour County has struggled to achieve traction with this initiative in past attempts due to barriers that rural communities often face. Two major efforts (a community collaboration event and the development of an engaging brainstorming kit) were devised by the FOGBF to create opportunities for open dialogue and establishment of a strong support system. This case study is designed to serve as a framework that can be replicated and adapted for other initiatives in Barbour County and similar communities that may face their own communication and collaboration challenges. 


\section{Acknowledgments}

I would like to take this opportunity to offer my sincere and humble appreciation to my committee: Eve Faulkes, Joe Galbreath, Kofi Opoku, and Michael Sherwin. Your continued encouragement, guidance and support throughout my graduate school experiences has helped me to grow as a designer and a person in ways I could not have imagined just a few years ago.

To the dedicated members of the Friends of George Byrer Field, thank you for your tireless efforts in making Barbour County a better place for us all.

Finally, I am particularly grateful for the never-ending love and support of my family. Thank you for always believing in me. 


\section{Table of Contents}

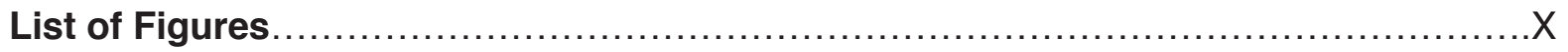

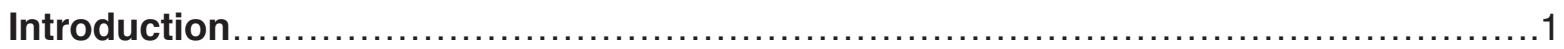

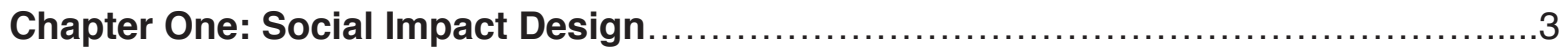

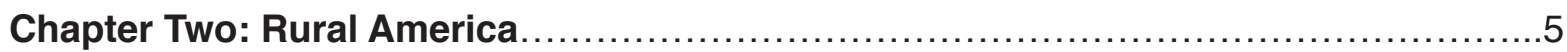

Chapter Three: Case Study: A Microcosm in Appalachia ...........................

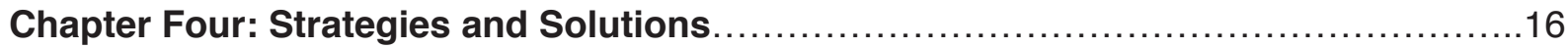

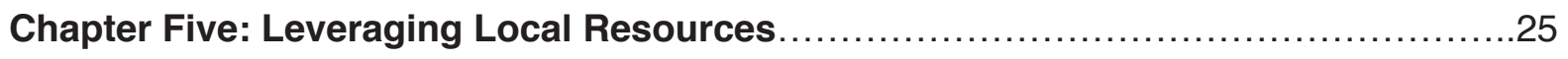

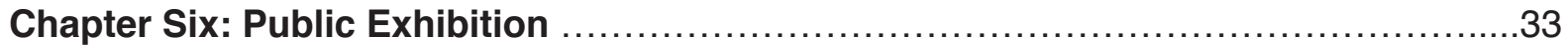

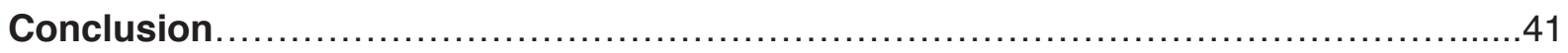

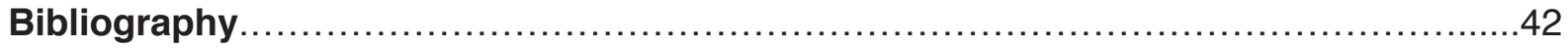




\section{List of Figures}

fig.(2.1) linear communication process as depicted by Lauren Schiefelbein

fig.(2.2) Modes of Interaction Model for Rural Communities as proposed by Lauren Schiefelbein

fig.(3.1) Aerial photograph of Philippi, the county seat of Barbour County-Lauren Schiefelbein, 2011

fig.(3.2) Drainage issues at George Byrer Field

fig.(3.3) Current conditions at George Byrer Field

fig.(3.4) Rendering of plans for new facility

fig.(4.1) FOGBF logo

fig.(4.2) FOGBF website home screen

fig.(4.3) Personas brainstorming activity and "Good Ideas!" sketchbook

fig.(4.4) Brainstorming guide sheet for community event

fig.(4.5) Sharing brainstorming results with group at event

fig.(4.6) Takeaway booklet given to attendees

fig.(4.7) Collaborative community event held in the media center of Philip Barbour High School

fig.(4.8) Data visualization posters displayed at community event as conversation starters

fig.(5.1) Process for disseminating information for the FOGBF initiative to encourage dialogue, advocacy and support to a broader, more diverse audience.

fig.(5.2) Wheel of Stakeholder Interaction

fig.(5.3) Kit box and components

fig.(6.1) Gallery space for Lauren Schiefelbein's MFA exhibition

fig.(6.2) Stills from video component in MFA exhibition

fig.(6.3) Case Study poster from MFA exhibition

fig.(6.4) Numbered posters for MFA exhibition

fig.(6.5) Data visualization posters displayed at community event as conversation starters

fig.(6.6) Visitors exploring the gallery space

fig.(6.7) Kit and Advocate booklet 


\section{Introduction}

In October, 2012, I was provided an opportunity to attend a business, design and social innovation conference in San Francisco, California. It was entitled, "Gain: AIGA Design for Social Value." The objective of the gathering was to assemble like-minded individuals from varying industries within the design fields and geographic locations to learn about the increasingly-used practice of design as a problem-solving tactic for social issues. The event presented me with opportunities to listen to some of the luminaries of social impact design, including one pioneer, Emily Pilloton, ${ }^{1}$ who vocalized the expanded role that designers play in finding solutions to some of the country's - and the world's - most challenging social, economic and health challenges. As I listened to Ms. Pilloton's presentation about her initiative, which has been named Project $\mathrm{H}^{2}$ many of her ideals and practices awakened my inner desires as a designer. Those aspirations are based upon utilizing my abilities to create positive, long-lasting change in rural communities that, while they have great potential, lack the support or resources to create a self-initiated revolution. Emily's example of working with an under served community in Bertie County, North Carolina reminded me of situations that I have experienced involving rural residents in my home state of West Virginia.

While this type of design practice had been touched upon in my previous undergraduate studies, it was not until I heard from the change-makers themselves that I truly grasped the capabilities to effect change that I already held as a designer. The creative attributes and skills that designers possess offer a unique perspective and skill set to problem-solving that other professions cannot provide. Among these qualities are the abilities to address three key areas: knowing who your audience is, appealing to them and reaching that target group most efficiently. At events across the country much like the AIGA Gain conference, design thinking ${ }^{3}$ and the inner workings of the design profession are being cross-pollinated with other aspects of professional knowledge, continually creating awareness of and spurring momentum for this unique problem-solving movement.

The first major project of my graduate school career involved this type of thinking and intent in finding a meaningful solution to a design problem. I was given the task of creating a permanent, two-room exhibit in a historic hospital located in Weston, West Virginia, the Trans-Allegheny Lunatic Asylum. The story of this iconic healthcare facility is one of a

1 Emily Pilloton promotes and teaches socially engaged design, and is best known for her lead role in Project $\mathrm{H}$. 2 Project $\mathrm{H}$ was founded by designer Emily Pilloton and consists of programs that essentially provide a design-based education that empowers rural youth to be the next generation of creative change makers in Bertie County, North Carolina.

3"Design thinking is a human-centered approach to innovation that draws from the designer's toolkit to integrate the needs of people, the possibilities of technology, and the requirements for business success." (Tim Brown, president and CEO of IDEO) 
caring city and its acceptance of neighbors who were different, yet valued, human beings. It also reflects the history of mental illness treatment in America. The project traced the slow steps of progress from a system that experimented with sometimes less-than-humane means of "normalizing" behaviors that were often misunderstood, to advancements over time which have led to a recognized and respected field of medicine... one that today continues to evolve and provide efficient pathways from mental illness to functional living. There is much to be learned about this important aspect of American life along the journey from the hospital's pre-Civil War era beginnings to modern times. And I believed that it could probably best be learned through the stories and memories of those who lived it over the years on both sides of the hospital's stone walls.

The two-room indoor exhibit that I created at the asylum was funded through a WV Humanities Council Grant. This exhibit primarily focuses on the stories told by former patients, workers, and community members who were once closely involved with the hospital. The culmination of my installation work, informational panels, timelines, tactile materials, book-making, screen printing and collections of personal quotes from interviewees has resulted in what viewers see today at the conclusions of their guided historical tours at the hospital. My main goal was to allow visitors to truly empathize with former patients and others in the community after learning the history, reading personal accounts and understanding stories of life in Weston. A secondary outcome was to help those touring the facility to consider the stigma of mental illness, even as it exists today.

The AIGA GAIN conference and this initial community-based project at the hospital marked the beginning of my interest in researching social design for the "greater good." I walked away from the event and my first immersion in the concepts feeling inspired to apply my skills and new knowledge to other initiatives that I felt strongly about back where I was born and raised. I am both passionate about my rural roots and committed to giving back to the community that has provided me with so much support over the years. Being exposed to social design at the AIGA conference steered my interests towards social impact design and has helped lay the intellectual framework for the work I have completed throughout my graduate school career. 


\section{Chapter 1: Social Impact Design}

Social impact design is not necessarily a sub specialty of the design profession. ${ }^{4}$ It may use some of the same creative, technical and organizational skills that students are taught in design school, but it includes an additional layer of value, a layer of thinking that is very human-centered, results-driven and one that seeks to create sustainable, transformational change. ${ }^{5}$

IDEO, a leader in social innovation, describes social impact design this way:

“... [it] applies to a broad spectrum of contexts. To designers, it is about the impact of products or services on individuals and groups of people. We look at the broader impact of all of the design work we undertake. We think about balancing the needs of the individual with the needs of the overall community. On every design project, we can consider the triple bottom line and take into account social, environmental, and economic impacts." 6

This does not mean that the profession can solely right all of the wrongs in the world, but it can certainly play an important role just as described by Emily Pilloton. She believes that design must serve as a strengthener in communicating a need, or distributing an existing message, rather than as an outside force that creates change for the stakeholders. Using design as a catalyst means utilizing design processes or principles to inspire something much greater. ${ }^{7}$

While Pilloton's work took place in a rural county in North Carolina, the ratio of urban versus rural social design practices in the United States tends to lean heavily toward urban areas. The research I have completed throughout my graduate school career has centered on various real-world examples and case studies that explore social design. Some of the more personally inspiring case studies have come from Project $\mathrm{M}$, a movement and a program for creative people who are already inspired to contribute to the greater good, and are looking for a platform to collaborate and generate ideas and projects bigger than themselves. ${ }^{8}$ The founder of Project M, graphic designer John Bielenberg, invites young designers to engage in social activism through design thinking. ${ }^{9} \mathrm{He}$ is widely known for his passionate belief that the design profession has much more to offer than to simply make things beautiful. With the necessary support and real world opportunities, Bielenberg

4 "Designing for Social Change," The Design Observer Group, Accessed February 18, 2015, http://designobserver.com/feature/designing-for-social-change/33188.

5 Emily Pilloton, Design Revolution: 100 Products that Empower People (New York: Metropolis, 2009)

6 "Design for Social Impact Workbook and Toolkit," IDEO, Accessed February 19, 2015, http://www.ideo.com/work/design-for-social-impact-workbook-and-toolkit.

7 Emily Pilloton, Design Revolution: 100 Products that Empower People (New York: Metropolis, 2009)

8 "Project M," Project M, Accessed April 6, 2015, http://www.projectmlab.com/Project-M.

9 "Pizza Farm," The Design Observer Group, Accessed April 13, 2015, http://designobserver.com/feature/pizza-farm/10597. 
believes that young designers can become socially responsible designers and make an impact on the world around them as they develop and move forward in their careers. Two examples of community-based projects from Project $M$ that incorporated social change and inspired me were PieLab and Pizza Farm.

PieLab ${ }^{10}$ is a local bakery in the small town of Greensboro, Alabama that also acts as an impactful platform for conversation, ideas and design. The business initially evolved from an event where homemade pies were distributed in Hale County, Alabama. The concept was designed to give vocal platforms to individuals within a comfortable, creative environment. The event demonstrated that bringing individuals together in a common space (with the help of good food) could lead to new and interesting conversations and ideas that can be transformed into positive change.

In the second example, Pizza Farm ${ }^{11}$ brought together a diverse community for an afternoon dedicated to what local farms had to offer in Falls Village, Connecticut. By attracting residents with free grilled pizza made with all locally-grown ingredients, the event created awareness about the health and economic benefits that local food has to offer both residents and area restaurants. That single event generated enough excitement in the small community that it led to plans for a local farmers' market. These case studies reveal that self-initiated change is not only possible for rural areas, but that the results are amplified when stakeholders and area residents are given a role in the process.

10 "Pie Lab," Project M, Accessed April 6, 2015, http://www.projectmlab.com/PieLab. 


\section{Chapter Two: Rural America}

Today, many once-thriving rural communities throughout the United States find themselves in a struggle to maintain a sense of identity, often due to demographic shifts that have occurred over time. ${ }^{1}$ Corresponding factors may include aging populations, limited employment opportunities, reduced services or the closings and/or relocations of businesses and industry. The sizes and numbers of rural communities are dwindling due to a lack of resources and services that are necessary to not only attract people to the area, but also to even maintain the families, citizens and employers already there. Without a steady economy and stronger resources, small town America faces a growing number of barriers in its efforts to stay relevant. Conversely, competing urban and suburban areas offer a larger variety of good-paying jobs, conveniences, attractions and infrastructures that keep people satisfied, engaged and interested in living and working in such areas, both short and long term.

When friendliness, charm, open spaces and a slower pace of living are not enough, small towns and rural areas are faced with the challenges of making their communities more desirable places to live. Design thinking has the power to offer solutions that can make the difference between a community that is vibrant and a community that plateaus or even withers away.

\section{Communication Challenges}

Not only can the physical geography be a barrier, but rural residents are generally more hesitant to support and accept change. An under served community can be slow to trust, especially when its citizens feel that decisions are being made for them. ${ }^{2}$ This is why it is important for designers to cultivate relationships with residents and include them into the conversation and decision-making process of making positive changes for their community. Effective communication with rural residents should allow them play a role and feel invested in the end solution. When these individuals are involved from the beginning stages, they are more likely to trust the project and project's leaders, assume a strong measure of ownership, and feel empowered to play a role in finding solutions that will better the future of their community. ${ }^{3}$ Further, as noted by Emily Pilloton, based upon the participation and success of local stakeholders, they can become potential change ambassadors for other community-based projects in the spirit of the well-known Chinese proverb: "Give a man a fish and you feed him for a day. Teach a man to fish and you feed him for a lifetime."

1 "Rural America at a Glance, 2014 Edition," United States Department of Agriculture Economic Research Service, Accessed April 6, 2015, http://www.ers.usda.gov/publications/eb-economic-brief/eb26.aspx.

2 Shea. Designing for Social Change, 27.

3 Shea. Designing for Social Change, 125. 


\section{Modes of Interaction}

Theoretical models of communication from the mid-1900s viewed the communication process as simply a linear process, where importance was placed on the message and how that message was transmitted to the receiver. ${ }^{4}$

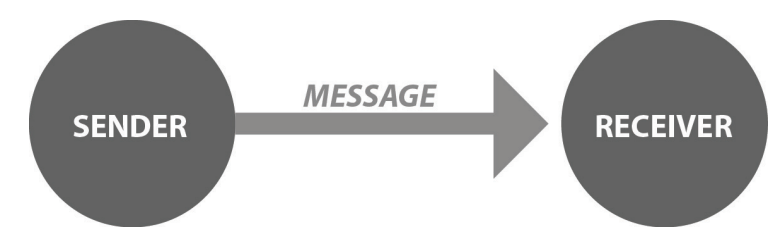

(fig 2.1) linear communication process as depicted by Lauren Schiefelbein

Today, communicating a message is considered to be a social process that is meant to bring together the communicator and the targeted audience in dialogue, where each party is sending and receiving information, encoding and decoding, eliminating "noise" and building knowledge. When one includes design thinking into that equation, greater importance is placed on how to approach the audience and creating a comfortable environment in which dialogue can take place.

One of the most celebrated American graphic designers, Milton Glaser, was quoted in a 2003 interview as saying,

"I would agree that design is essentially a dialogue, not a monologue. In most cases your role is to serve a client. But then in the area of your own personal ethics, if you have a relationship with a client which is based on more than professionalism, if you like them and trust them and they trust you and like you, then the possibility for persuasion becomes much greater."5

The primary purpose of dialogue pertaining to a particular issue is for those involved to become better educated on the problem, as well as understanding one another's views of it, which will help solve conflict or remove barriers. Participants therefore develop a greater understanding of the issues at hand while giving all a platform to voice their ideals and opinions.

When considering how to best create dialogue with a rural audience, one must decide how to most efficiently disseminate information in a way that it will be accepted and trusted. Audience segmentation is typically arranged by demographic, geographic or behavioral factors. Segmenting the audience allows you to do more with limited resources and can

4 Smith, J. "Basic Communication Model." The Pfeiffer Library Vol. 25, 2nd Edition, 1998 (1978): 1-2. Accessed April 14, 2015. snu.edu/ jsmith/library/body/v25.pdf.

5 Milton Glaser and Jonathan Barnbrook, "Milton Glaser and Jonathan Barnbrook Discuss Design's Rules of Engagement." Creative Review 23, (2003) Accessed November 16, 2014. 
increase the effectiveness of your messaging and engagement plan. ${ }^{6}$ While segmentation can be based broadly on personas, there are many useful audience segmentation models available.

The most common approach to audience segmentation is by demographics-distinguishing stakeholders by race, gender, ethnicity, income, or age. Even though a widely used option, the correlation between demographics and the actual determinants of behavior is imperfect. ${ }^{7}$ While these methods divide the stakeholders into well-defined categories, demographic and geographic factors ignore the variables that influence behavior or thinking. Qualitative research methods such as focus groups and interviews can offer insight into these varying characteristics that exist within the demographic or geographic constraints. One challenge with this method is ensuring that a particular demographic is being well-represented during focus-groups or interviews. While not an exact science, this approach can help designers make informed decisions when attempting to create dialogue with the target audience. Identifying a more suitable audience segmentation method allows the problem to be framed in a manner which will then, in turn, shape the pathway for finding an appropriate solution.

Through my personal observations and from analyzing a number of case studies that have used design as a vehicle for communicating a message in rural communities, I propose a new audience segmentation approach. This method follows three primary modes of interaction that designers would be wise to consider: individual, group, and mass.

Following is a snapshot overview of each:

1. Individual: person-to-person interaction or word of mouth -Positives: personal, more detailed information -Negatives: small reach -Channels: face-to-face

2. Group: organization to organization, business, agency, club, etc. -Positives: broader reach than individual interaction, more personal than mass -Negatives: time consuming, labor intensive

-Channels: group meetings, open house, group activities, events

6 Audience segmentation is the process of dividing an audience into smaller groups with the goal of identifying groups whose members are similar to each other along dimensions that are meaningful to the context of the project goals.

(Marketing Public Health, Strategies to Promote Social Change by Michael Siegel and Lynne Doner, 303.)

7 Maibach, Edward. Designing Health Messages Approaches from Communication Theory and Public Health Practice. Thousand Oaks, Calif.: Sage Publications, 1995. 188. 
3. Mass: organization to the general public

·Positives: broad reach

-Negatives: associated costs, less personal

-Channels: TV, radio, Internet, social media, newspaper, billboard, posters

\section{Modes of Interaction}

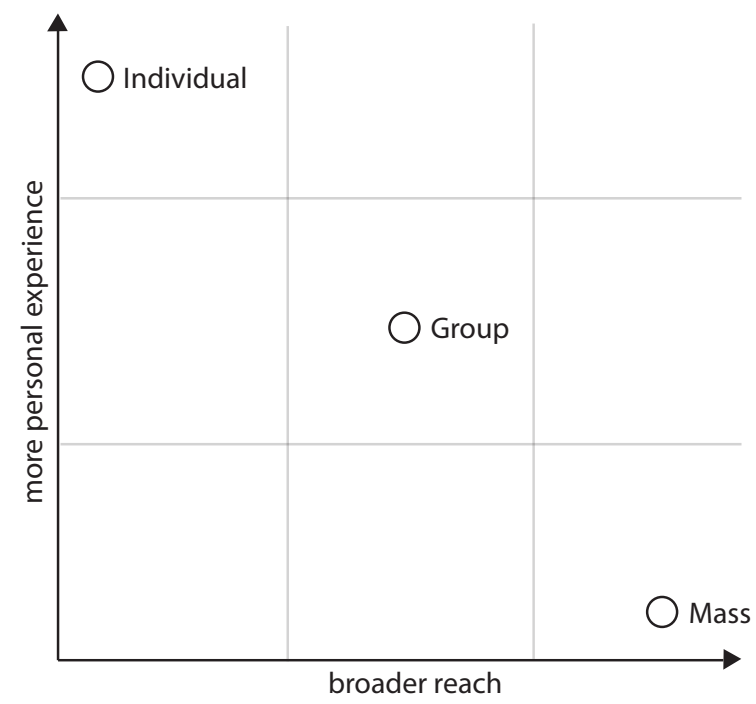

fig. (2.2) Modes of Interaction Model for Rural Communities as proposed by Lauren Schiefelbein

I believe the above three modes of interaction to be the best solution for reaching out to a rural audience reluctant to accept change. Especially focusing on the individual and group modes will allow for a more personal experience when engaging residents in dialogue about the project. The mass component is beneficial in reaching a larger audience, but you lose the opportunity to create a more personal interaction.

\section{Designing Maximum Impact}

My research focuses on the designer's role in facilitating dialogue within rural communities to create positive social change. This process requires special attention, different from urban or suburban environments where community members live in a more concentrated area and their behaviors, attitudes and characteristics are more easily tracked. The scattered and often independent nature of residents in rural communities, along with common social factors, present communication barriers that need to be evaluated before a decision on how to best utilize design in the dissemination process can be finalized. In summary then, a carefully-tailored strategy of design interaction in communicating a message has great potential for allowing more open dialogue, greater levels of support and increased advocacy surrounding an issue, challenge or problem in rural communities. 


\section{Chapter Three: Case Study, a Microcosm in Appalachia}

\section{Barbour County, West Virginia}

I have always considered Barbour County to be the heart of West Virginia due to its shape and physical location within the state. The county is comprised of several small rural communities, alternately wooded and open lands, and a population of 16,770 residents. Approximately $86 \%$ of Barbour County is considered rural. ${ }^{1}$ Nestled at the western foot of the Appalachian Mountains, it is perhaps best known for its county seat, Philippi, being the site of the first land battle of the Civil War. While it is blessed with natural beauty and good people, it is a chronically low socioeconomic county in one of the most unhealthy states of the United States. For decades, studies and reports have regularly labeled the Mountain

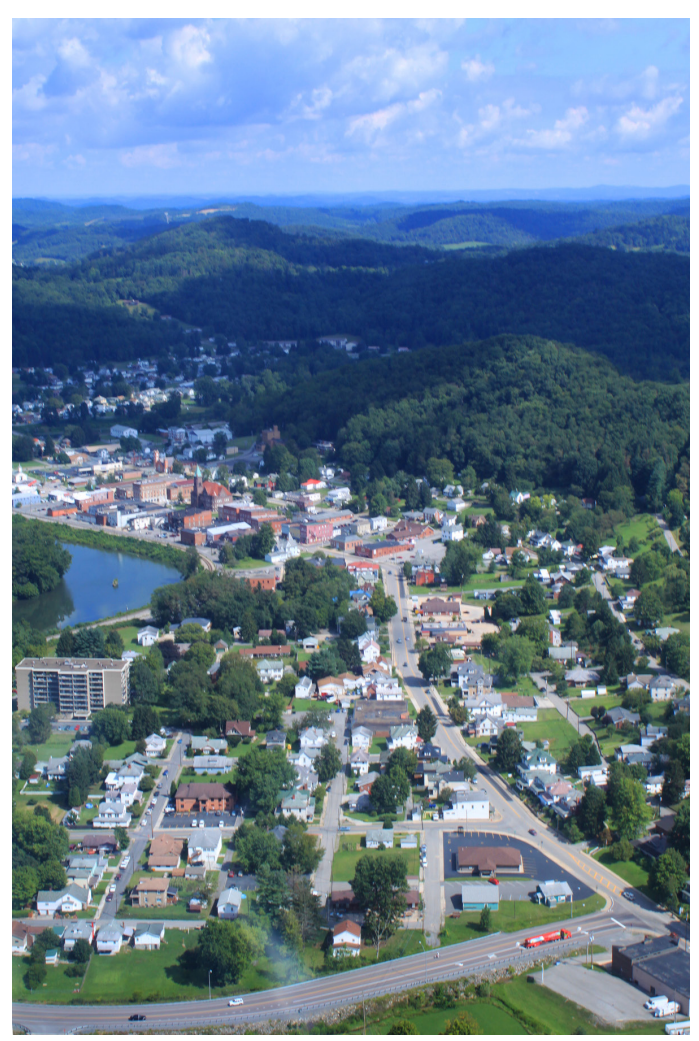

fig.(3.1) Aerial photograph of Philippi, the county seat of Barbour County-Lauren Schiefelbein, 2011
State as one of the most unhealthy in the USA. Barbour County, located in north-central West Virginia ranks in the bottom half, 34th of the 55 counties, in overall health. Similarly, West Virginia and Barbour County rank near the very bottom nationally in areas such as physical activity, smoking, obesity and diabetes. ${ }^{2}$ Once an important part of a booming coal region, Barbour County has never fully recovered economically from the coal industry's exodus in the late 1970 s and 1980s.

\section{Tackling an Acknowledged Problem}

In many rural, low-socioeconomic areas, the recommended amounts of physical activity are not often easily attainable or affordable for residents. Barbour County currently lacks a safe, modern public facility for running, walking and other outdoor exercise activities. The 50-plus year old athletic complex at Philip Barbour High School, while ideal in its central and accessible location, is outdated, inadequate and uninviting. The natural grass field was constructed at the bottom of a natural three-sided bowl. It is clay-based and is subject to major drainage issues any time it rains. The running track which encircles it is formed by clay and loose

1 "Compare Counties in West Virginia," County Health Rankings \& Roadmap, Accessed January 18, 2015, http://www.countyhealthrankings.org/app/west-virginia/2015/compare/additional?counties=001.

2 "West Virginia Health Factors" County Health Rankings \& Roadmap, Accessed January 18, 2015, http://www.countyhealthrankings.org/app/west-virginia/2015/rankings/factors/overall. 
cinder, resulting in an uneven, easily rutted surface. But the potential for a tremendous site exists. Surrounded by a scenic landscape, George Byrer Field rests upon the largest high school campus, by acreage, in the state of West Virginia. The athletic complex has served many thousands of students since 1963-64. Rich in its history and importance to the community, the current field at Philip Barbour High School was named in honor of George A. Byrer, the original football coach for the only high school in the county. The present field and its buildings have remained virtually unchanged in the more-than half-century that Philip Barbour High School has been in existence.
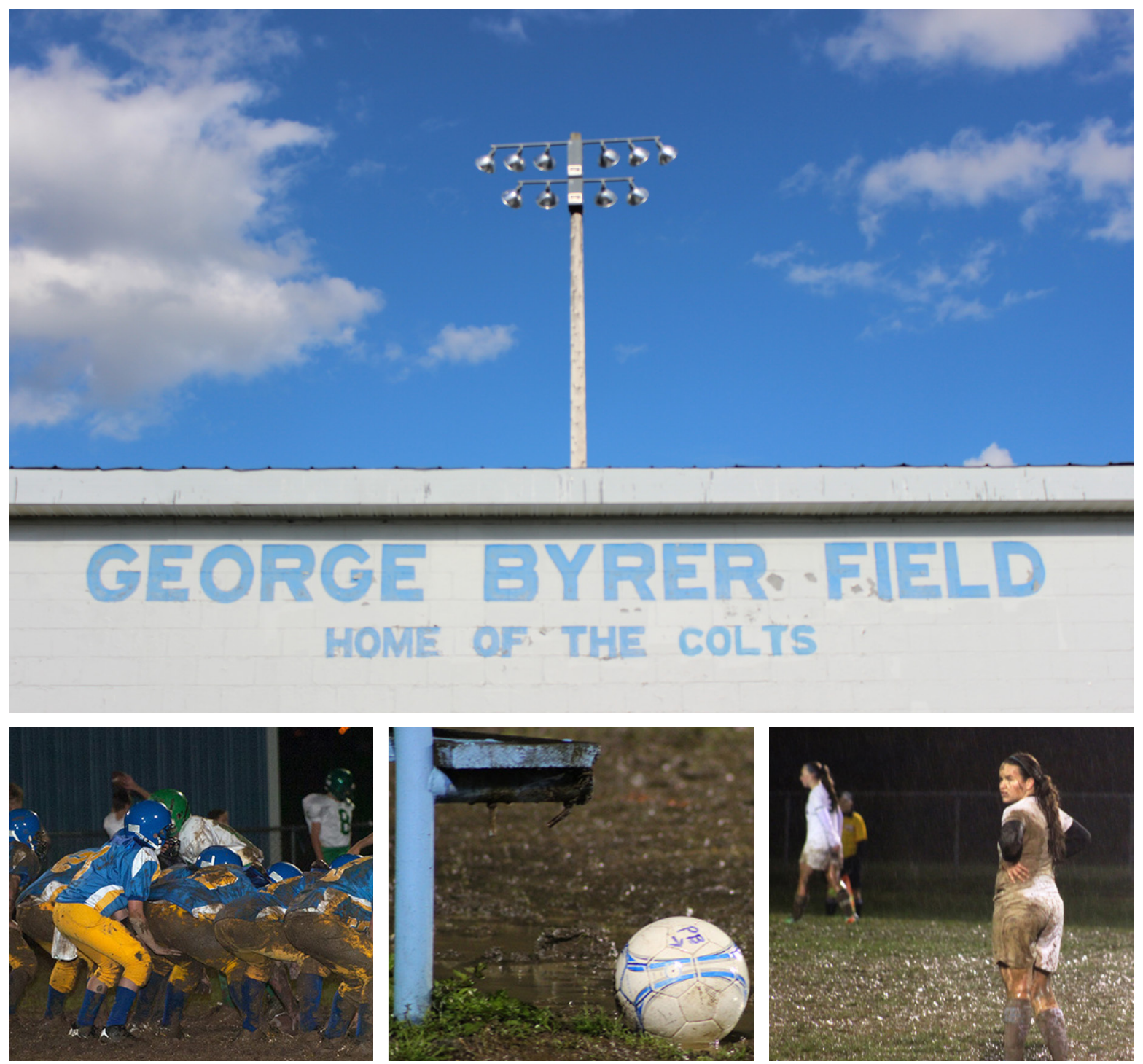

fig. (3.2) Drainage issues at George Byrer Field 

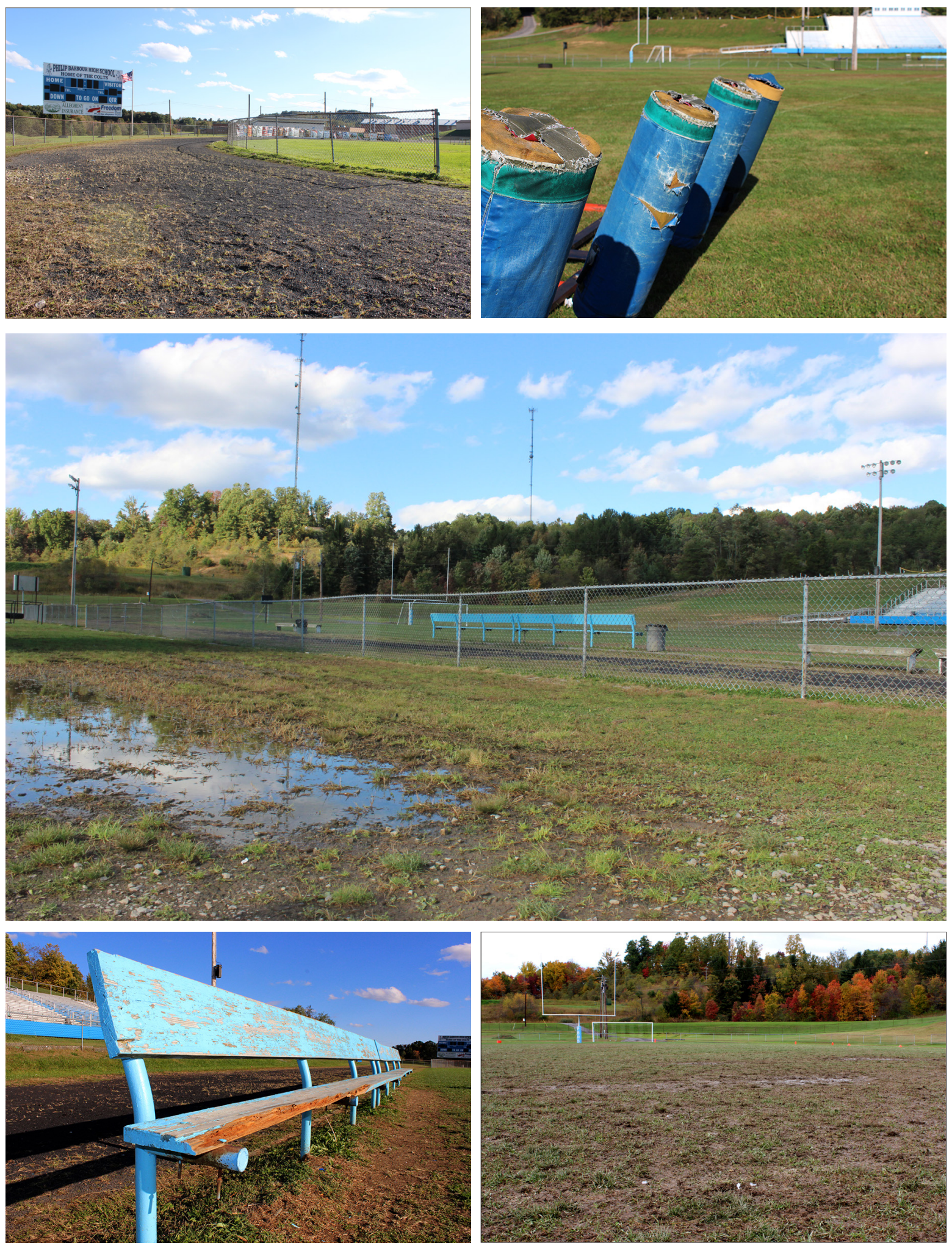

fig. (3.3) Current conditions at George Byrer Field 
Although four (4) bonds for new school buildings have been approved over the past half century, Barbour County has never passed an excess school levy in its history. In July 2014, Mary Vagner, the school superintendent of the Chubbuck School District No. 25 in Idaho, provided concise definitions of these two types of tax proposals to help differentiate between them:

"An excess school levy is supplemental to the district's general fund, which pays for the operation of the school district. It includes salaries and benefits, supplies and equipment, materials and utilities, fuel and extracurricular program needs."

On the other hand, "a bond is also voted upon by the people and, if approved, provides money that is specific to fund building improvements or specifically to do remodeling or to build new facility construction." 3

\begin{tabular}{|l|l|l|l|}
\hline Bond/Levy & Date & Result & Amount \\
\hline Bond & 1960 (May10) & Passed & $\$ 950,000.00$ \\
\hline Bond & 1969 (June 9) & Passed & $\$ 1,080,000.00$ \\
\hline Levy & 1975 (December 16) & Failed & $\$ 1,942,800$ (5 years) \\
\hline Levy & 1978 (August 18) & Failed & $\$ 4,108,000.00$ \\
\hline Levy & 1978 (September 29) & Failed & $\$ 4,108,000.00$ \\
\hline Bond & 1979 (June 14) & Passed & $\$ 5,429,583.00$ \\
\hline Levy & 1991 (March 14) & Failed & $\$ 597,929.00$ \\
\hline Levy & 1995 (March 18) & Failed & $\$ 767,091.00$ \\
\hline Bond & 1998 (November 3) & Failed & $\$ 8,000,000.00$ \\
\hline Bond & 2000 (March 18) & Passed & $\$ 7,500,000.00$ \\
\hline Bond & 2012 (November 6) & Failed & $\$ 5,480,000.00$ \\
\hline Levy & 2012 (November 6) & Failed & $\$ 2,191,456$ (5 years) \\
\hline
\end{tabular}

Understanding the reasons behind general attitudes within a community is an important part of the research process. In comparison with surrounding counties, Barbour County is the only district that has never passed an excess school levy and is one of only two counties that is not currently receiving any supplemental funding through a bond or levy.

This chart represents Barbour County and surrounding counties' bonds and levies, both historically and currently. "Ever" in the headings indicates within the history of the county's school system. "Current" in the headings indicates that the levy or bond is active as of 2014-15.

Source: West Virginia State Auditor's Office, "Rates of Levy (State, County, School and Municipal), 2014 Tax Year, Fiscal Year Ending June 30, 2015"

3 "School Levy or Bond: What's the Difference," Local News 8, Last modified March 12, 2013, http://www.localnews8.com/news/School-levy-or-bond-What-s-the-difference/19231400. 
A closer look at the history of bond and levy attempts in Barbour County reveals a general lack of support since 1960. Bonds that have eventually passed in the county often took multiple attempts.

\section{Barbour County's History of Passed/Failed Bond \& Levy Attempts (1960-Present)}

\begin{tabular}{|l|c|c|c|}
\hline County & Levy (Ever) & Levy (Current) & Bond (Current) \\
\hline Barbour & N & N & N \\
\hline Harrison & Y & Y & Y \\
\hline Lewis & Y & Y & Y \\
\hline Marion & Y & Y & Y \\
\hline Monongalia & Y & N & Y \\
\hline Preston & Y & Y & N \\
\hline Randolph & Y & N & N \\
\hline Tucker & Y & Y & N \\
\hline Upshur & Y & & Y \\
\hline
\end{tabular}

Bond and Levy data provided by the Barbour County Board of Education (2014)

The school system operates on a "bare bones" budget that allows virtually nothing extra to be purchased or constructed. Most recently, in 2012-13, both a levy and a bond were defeated at the ballot box with only $37 \%$ of residents supporting the bond that would have paid for this "field of dreams."4 Other serious attempts to renovate and modernize the facility date back to the late-1970's when the board of education had to cancel plans that had been blueprinted due to lack of funding. Another community organization, the Philip Barbour High School Foundation, attempted to raise money for the project as recently as 2010, but disbanded before finding any significant success.

4 Data provided by Barbour County Board of Education, 2014. Anecdotal responses shared by voters to school 
Observational research and interviews with local residents reveal a general resistance to change, especially when tax dollars are involved. Some of the primary reasons cited by the voting public for not supporting the 2012 Bond, as cited by education officials in the county include,

WHAT WE HAVE IS GOOD ENOUGH.

Not all residents are aware of the poor conditions of the current facility at Philip Barbour High School, or consider the fact that this is the only outdoor facility for the entire county.

\section{WE DON'T WANT TO PAY MORE TAXES.}

Some residents who are on a fixed or low income cannot afford to pay the extra taxes that would come with a school bond. Others simply say that this is not a good time. Many community members do not see this facility directly benefiting them or their families.

\section{WE HAVE BEEN DECEIVED BEFORE.}

Some residents expressed skepticism about supporting this bond due to negative perceptions and rumors about misuse of tax dollars from previous bonds and levies in history. (e.g. hospital, emergency services, school system, etc.)

In late 2013, a cross-section of caring citizens joined forces to create the Friends of George Byrer Field (FOGBF) organization. Among the members are business people, area professionals, school personnel, social agency representatives, alumni, parents, students and other interested parties. This group of dedicated volunteers would not accept defeat and made plans to construct a campaign built around increasing community knowledge, interest, trust and enthusiasm. The FOGBF is in the process of seeking support for a new facility through branding, messaging, and creative communication and fundraising efforts. The reasons provided for not supporting past bonds helped inform the group's decisions as they have moved forward. Previously proposed as an athletic complex for the youth of Barbour County, the scope of the project was broadened to appeal to a larger, more diverse audience in hopes of gaining more support.

\section{The Friends of George Byrer Field}

As noted, the Friends of George Byrer Field (FOGBF) is a grassroots organization comprised of about two dozen volunteers from various professions who are working to raise the $\$ 2$ million necessary to provide the youth and local community with a new outdoor facility for athletic and performance events and public exercise. After three failed ballot attempts by the board of education and the local foundation within the past decade, and with a still-weak economy dampening the area's general outlook, the organization must 

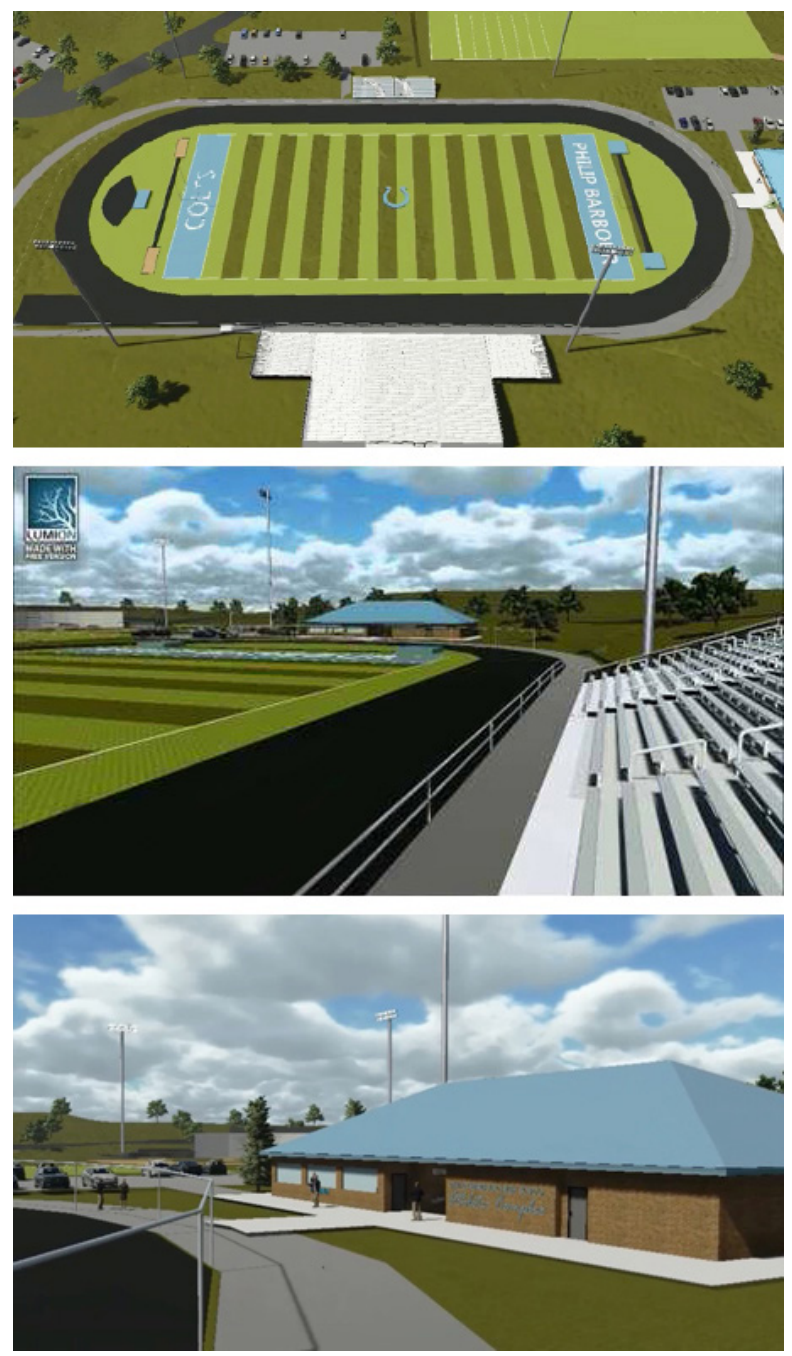

fig. (3.4) Rendering of plans for new facility

rely on donations, fundraising activities and community support to reach its goal by the 2016-17 school year.

\section{Breakdown of Cost:}

New Turf Field: \$750,000

Nine Lane Track: $\$ 500,000$

Lights: $\$ 250,000$

Structure Facilities: $\$ 500,000$

Total: $\$ 2,000,000$

Substantial renovations and construction will be necessary to create the necessary state-of-the-art facilities in this ambitious project. The major components will include: a new turf multi-purpose field, a new ninelane track, a modern lighting system, a new field house, improved public restroom facilities, and a concession stand. Not only would a new facility promote healthier living, but as the only high school in the county, it will also provide a source of pride for all that reside in, work in and support Barbour County.

While the ultimate goal of the Friends of George Byrer Field is raise substantial funding to make this project a reality, my goal as a designer is not based upon the fundraising aspect. My role within the organization is to encourage community support surrounding this initiative and to create a process of communicating with rural audiences that can be duplicated for future projects in Barbour County and replicated in rural areas facing comparable challenges.

I attended my first FOGBF meeting in June of 2014, and quickly saw an opportunity to implement design thinking into the group's game plan. While they had many good ideas and were dedicated to finding a solution, the group was having trouble gaining solid traction in moving forward. I was confident that my design skills could benefit the cause and light a spark within the organization. The members have embraced my participation and have given me virtual free reign to incorporate my design ideas and philosophies. 


\section{Chapter Four: Solutions and strategies}

\section{Implementing Design Thinking}

"We moved from thinking of ourselves as designers to thinking of ourselves as design thinkers. We have a methodology that enables us to come up with a solution that nobody has before... What we, as design thinkers, have, is this creative confidence that, when given a difficult problem, we have a methodology that enables us to come up with a solution that nobody has before." ${ }^{-}$-Tom Kelley, IDEO

Because the George Byrer Field problem had not been successfully addressed for decades, Tom Kelley's words carried meaning. With my welcomed role on the committee, design thinking was incorporated early in the FOGBF's process to help bolster support from the community. It was clear that the project could not succeed based upon past strategies alone, such as raffles, 50/50 drawings, solicited donations and the sales of items.

Therefore, the FOGBF decided to think "outside the box" as well as traditionally. With my guidance and assistance, we started by creating a branding program and then developed multiple presences on social media. By utilizing design thinking, our novice fundraisers also began brainstorming other potential benefits beyond sports (e.g. health, economic, and social aspects) that could result from building the new state-of-the-art athletic, performance and fitness facility in Barbour County.

In any community where residents can be skeptical and unwilling to listen to new ideas and invest in the future, it is vital to create legitimacy within the group with which one is

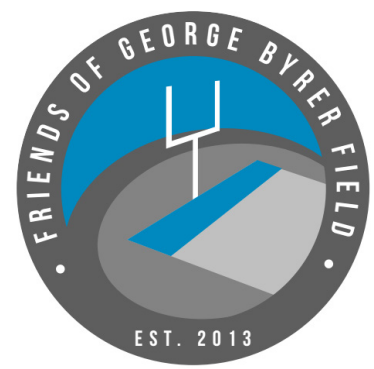

fig. (4.1) FOGBF logo working. Branding is a great place to start. By developing a visual consistency to carry throughout a campaign, the organization became able to demonstrate a higher level of authenticity and professionalism while building a relationship with the community. As the committee's visual designer, I developed a logo (fig. 4.1) that represented the group and its initiative. This particular logo acts as a visual representation of the lone football field and track in the county, which automatically connects the viewer's mind to George Byrer Field. This creates a very familiar feel for the audience. The FOGBF logo is used on any and all print, web, or video material that is placed in front of the public.

1 "IDEO's David Kelley on Design Thinking," Fast Company, Accessed April 16, 2015, http://www.fastcompany.com/1139331/ideos-david-kelley-design-thinking. 
An informational website ${ }^{2}$ (fig.4.2) was developed to provide an easy-to-follow breakdown of project goals, benefits and costs, while the showing progress of donations made over time. My role in the website development was to provide content and imagery to a web designer who could then code a site to inform and engage visitors. Using the website and social media are great tools to help to create a constant presence in the online community, and is especially helpful in reaching out to the younger generation to capture their interest, and educate and keep them informed about the project. The FOGBF developed Facebook,

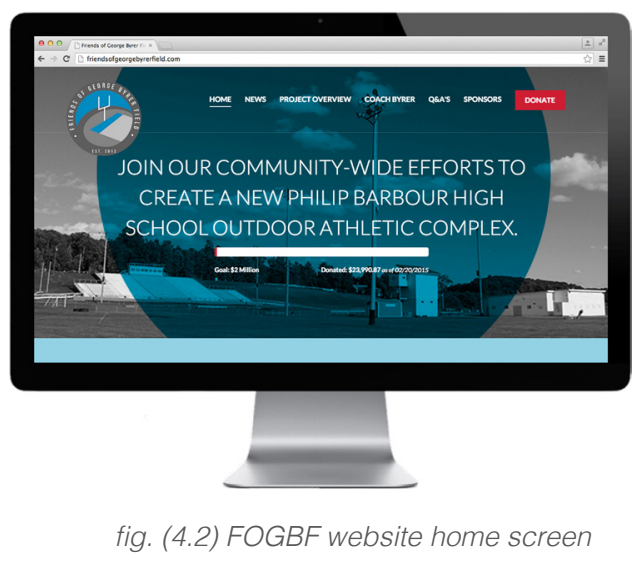

Twitter, Instagram, and Linkedin accounts in its early months to connect with current students, parents, community members, alumni, business persons, and organizations. By posting updates and periodically adding photos, quotes and campaign graphics, these efforts will keep the project in front of the stakeholders and potential contributors. This "front burner approach" will let them know that the FOGBF is serious about finding meaningful solutions to a great cause, and that it does not plan to give up any time soon.

While it is a valid tool in today's world, I realize that the group cannot rely on social media alone to reach its target audience. For one thing, the Internet is not widely-accessible in many rural areas.

"In rural America, only 60 percent of households use broadband Internet service, according to a report released Thursday by the Department of Commerce. That is 10 percent less than urban households. Overall, 28 percent of Americans do not use the Internet at all." 3

Taking this into consideration, it was clear that, although it is cost-efficient and has a wide reach, reliance on the internet as the main channel of communication would not be the best solution for reaching our rural audience. The committee then began to focus on the best solution for reaching a broad audience that would still allow for meaningful dialogue about this project. After weighing the options, I proposed that the committee host a collaborative community event at a centralized location and invite stakeholders from business, agencies and community organizations to participate in an evening of well-designed and project-

\footnotetext{
2 The organization's website is friendsofgeorgebyrerfield.com (or fogbf.com), and was developed by designer, Kelly Barkhurst (kellybarkhurst.com)

3 "Digital Age Is Slow to Arrive in Rural America," New York Times, Accessed March 11, 2015, http://www.nytimes.com/2011/02/18/us/18broadband.html.
} 
specific brainstorming activities. It was made clear to those invited that this would not be a fundraising event, but an opportunity for locals to have a voice in this initiative and contribute by simply participating in our event.

My decision to bring various segments of the community together for a special event stemmed from my research on the Project M initiatives, Pie Lab and Pizza Farm. Both projects offered a comfortable, neutral meeting spaces for community members to gather, learn from one another, and converse. While Pie Lab was a singular event that evolved into a permanent establishment, Pizza Farm was a one-time program that provided a day full of fellowship based upon learning what local farmers had to offer the community. Much like Pizza Farm, my goal was to design a community event that brought residents together to create awareness of the FOGBF initiative and reveal what benefits a new multi-purpose facility could offer the residents of Barbour County.

\section{Engaging Stakeholders}

Residents were invited to attend this collaborative community event hosted by the FOGBF on January 29, 2015 to brainstorm alternate uses for the new athletic facility. In the latest attempts to pass this project as a school bond, it was described as an athletic field for the youth of Barbour County. While it would indeed provide a newer and safer space for the student-athletes, the FOGBF realized that broadening the scope of the project would capture the attention of more residents, which could transfer to greater support for the initiative. The goal was to work with the stakeholders to reframe the project in a way that would encourage more interest, involvement and investment from the community.

Over 130 invitations for the event were mailed out to local organizations, agencies, businesses, schools, local government and community leaders. A list of these individuals was compiled by the committee to include a cross section of the county. The goal of the FOGBF was to receive feedback from individuals with varying backgrounds and perspectives on the initiative as a result of the event. Of those 130 invitations mailed out, approximately 40 individuals attended the event, held at the media center of centrallylocated Philip Barbour High School, within sight of George Byrer Field.

As individuals entered the main doorways, they were welcomed by FOGBF committee members who assisted them in signing in and retrieving their informational packet complete with a name tag, event schedule, and all materials necessary for the event activities. They were then directed to the high school's library-media center where they were greeted by a series of posters on easels that touched upon the content that they would be hearing about when event got under way. 
The introduction of any gathering must begin by capturing the attendees' attention and providing a framework for the remainder of the event. The evening began with presentations from the two committee chairs of the Friends of George Byrer Field, who gave overviews of the costs and goals of the initiative. The audience then heard from the Philip Barbour High School principal who conveyed the great need for a new facility, and what it would mean for the students in the county. As the committee designer, I then spoke to the group about the potential that this facility has to directly address local health and fitness concerns for all ages and demographics, using charts, graphs and statistics. From that point, I transitioned into imagining this facility as a community gathering place for Barbour County, one of which residents could be proud, and then introduced the brainstorming activities that would follow.

An instructional sheet that I had prepared laid out the the tasks to be completed as part of the small group brainstorming sessions that I planned. (fig. 4.4) The sheet first asked participants introduce themselves to one another and then delegate different tasks to individuals within the small group. Part I of the brainstorming session asked group members to consider the ways that a new multi-purpose facility in Barbour County could positively affect the life of a given persona. The persona exercise provided each group a different typical but fictional individual, one that represented a different demographic in Barbour County.

During Part II of the session, the groups were then encouraged to think about the facility as more than a football field and to explore other possible uses for this facility. Each small group, made up of 7-8 individuals, was given a "Good Ideas!" brainstorming sketchbook to record and/or sketch their thoughts and ideas.
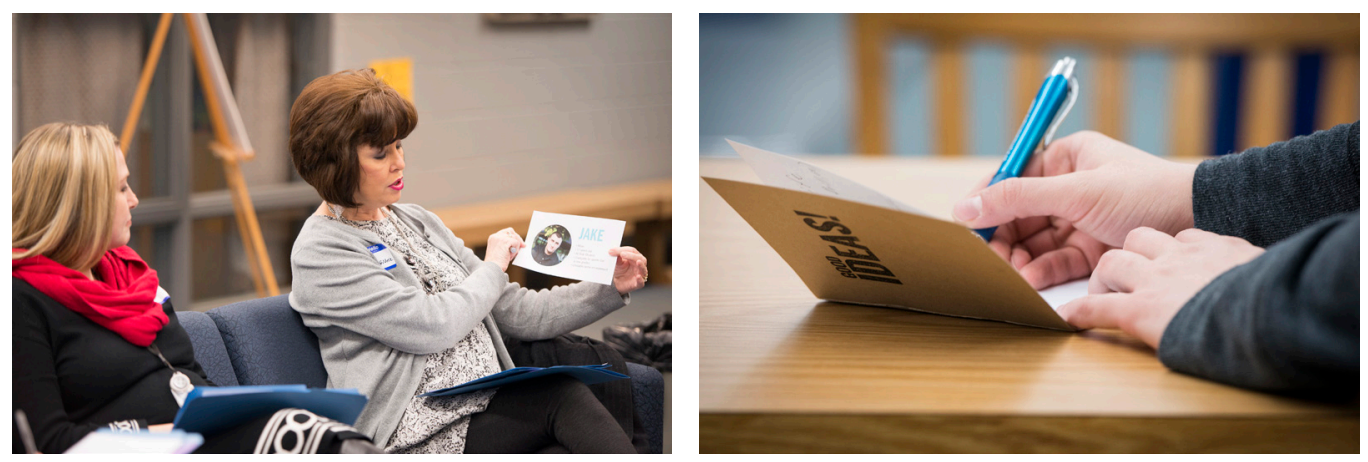

fig. (4.3) Personas brainstorming activity and "Good Ideas!" sketchbook 


\section{BRAINSTORMING (40 minutes)}

1. If you do not already know everyone in your group, take a short moment to introduce yourself and what business/company/organization you are associated with.

\section{Each group needs to choose one leader, one recorder and one reporter.}

Leader: Keep the group on track and engage all members in the small group.

Recorder: Write down all ideas presented by the small group.

Reporter: Share your group's findings with all participants.

\section{Brainstorming Activity:}

Part I: Personas

You have been provided with a specific persona. Consider this person's lifestlye, career, family life, eating habits and exercise habits. Write down any ideas that your group comes up with on how a new athletic, performance and fitness facility could be beneficial to his or her life.

Definition: A persona represents a cluster of users who exhibit similar behavioral patterns in specific situations. They act as 'stand-ins' for real community members and help guide decisions about effectively communicating to a broader audience about the project.

Part II: Creative Uses

Now that you have considered your group's persona, think about how a new athletic, performance and fitness facility could benefit each of you personally, or your business/organization. What are other creative uses for this new facility?

\section{Report Findings}

Choose your top three ideas for your persona, and the top three ideas for creative uses. The reporter should share these ideas with the rest of the group.

Participants are encouraged to write down ideas in their "Good Ideas!" booklet they received with the brainstorming packet.

fig. (4.4) Brainstorming guide sheet for community event 
When the small groups reassembled to report their ideas to one another, it became clear that this facility could truly act as the community hub and touch the lives of not only the youth of Barbour County, but potentially all residents. This reflection process gave the stakeholders an opportunity to realize that by discussing the project, through organized dialogue, they had a role to play in the process of providing leadership for the community. They were made to feel like they were contributing to a cause that would provide Barbour County with social, economic, and health benefits, all while creating a more closelyknit community. As the reporter from each small group presented the results of his/her respective brainstorming session, an impressive list was compiled to reflect the overall results.

\section{Brainstorming Results}

Relay for Life location

Community-wide yard sale

Adult recreational leagues

Outdoor fitness classes

Movie night (pop-up screen/projector)

Outdoor concert venue

Graduation

Special olympics

P.E./Band classroom

Walking club

Silver sneakers

Field day for community

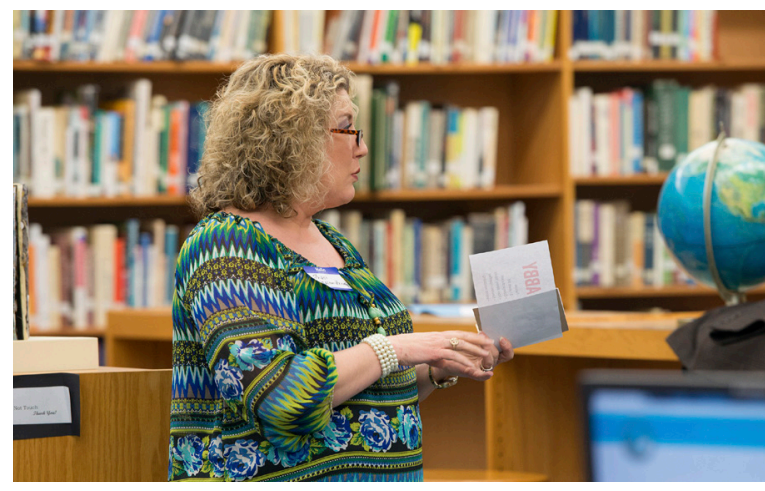

fig. (4.5) Sharing brainstorming results with group at event

Internship for college students (help with upkeep)

Switch from source of embarrassment/source of pride

Free fitness classes

College group activities

Alumni events, football game

More events=more business for county (restaurant, hotel, gas, etc.)

Concession stand opportunities for other groups or organizations to fundraise

Advertising local business with signs

Emergency drills

Centralized area for emergency services

Outdoor student craft fair

Add sun shelter/pavilion for protection (available for parties/reunions)

At the conclusion of the event, all attendees received two takeaway booklets, (fig. 4.6), one for themselves and additional copies to share with friends. I designed these booklets to provide a summary of information from the evening's presentations, and to also include some thought provoking graphics and statistics that could be used to generate further conversation regarding the benefits of the FOGBF initiative. The evening concluded with the awarding of door prizes (many related to the theme of healthy living), a light meal provided by the FOGBF organization and specially-designed complimentary tickets to that evening's high school basketball game. 


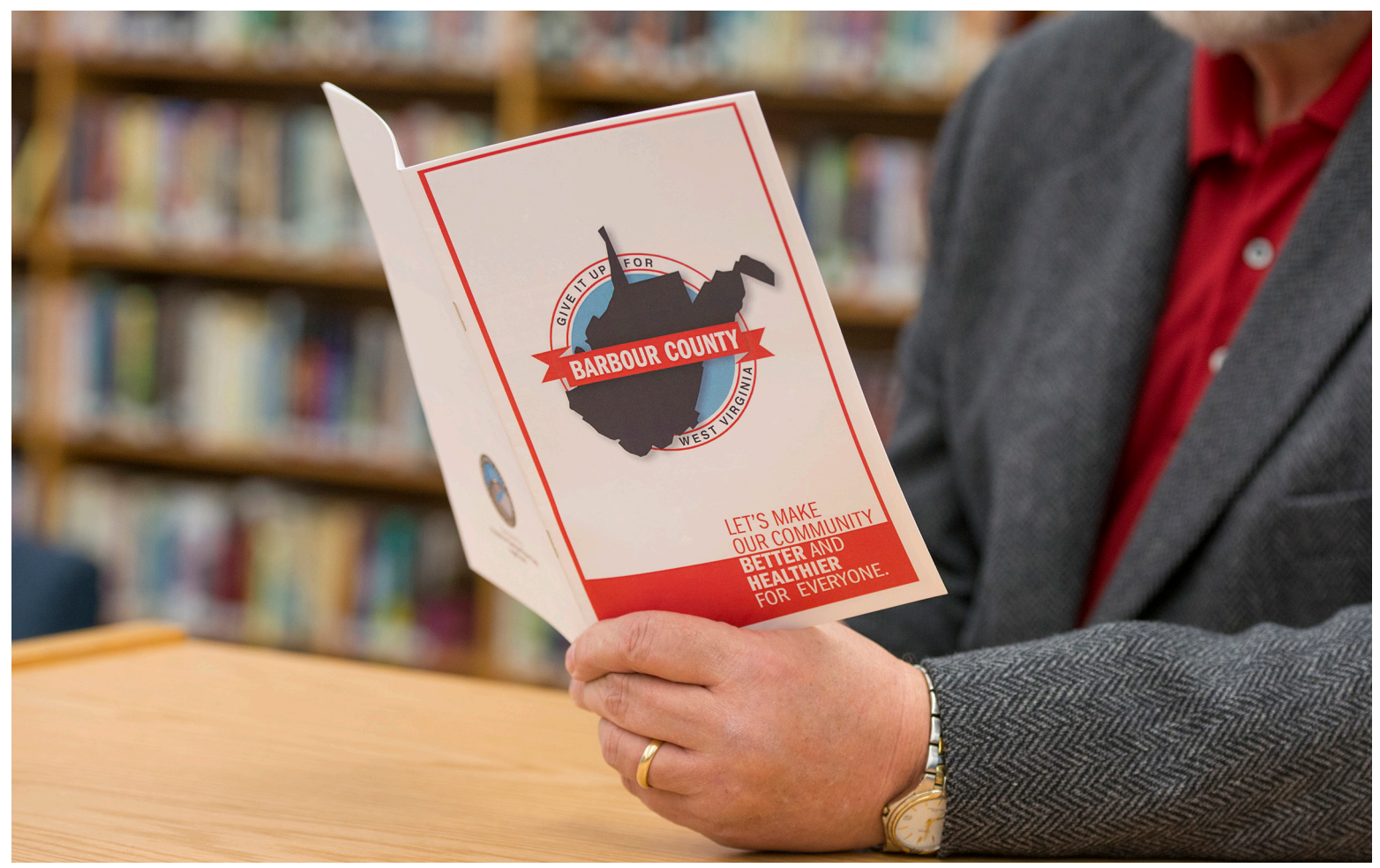

fig. (4.6) Takeaway booklet given to attendees

Anecdotal feedback by the participants showed that the collaboration event was truly a key in unlocking the minds of attendees as it allowed them to realize the potential of what a new performance, athletic and fitness facility in their community could look like and how the transformation would make the community more livable, healthy and inviting. A post-event evaluation showed that the event was successful in educating and engaging the attendees. Many of the responses suggested the idea of "taking the show on the road" to reach other local groups.

Taking the feedback into consideration, the FOGBF committee began to search for a solution to provide the same content and opportunity for participation to a broader audience. Looking back at the three modes of interaction, the group decided to move their focus from bringing individuals to them to reach out to existing groups or organizations that have already exhibited that they care about the future of Barbour County. 


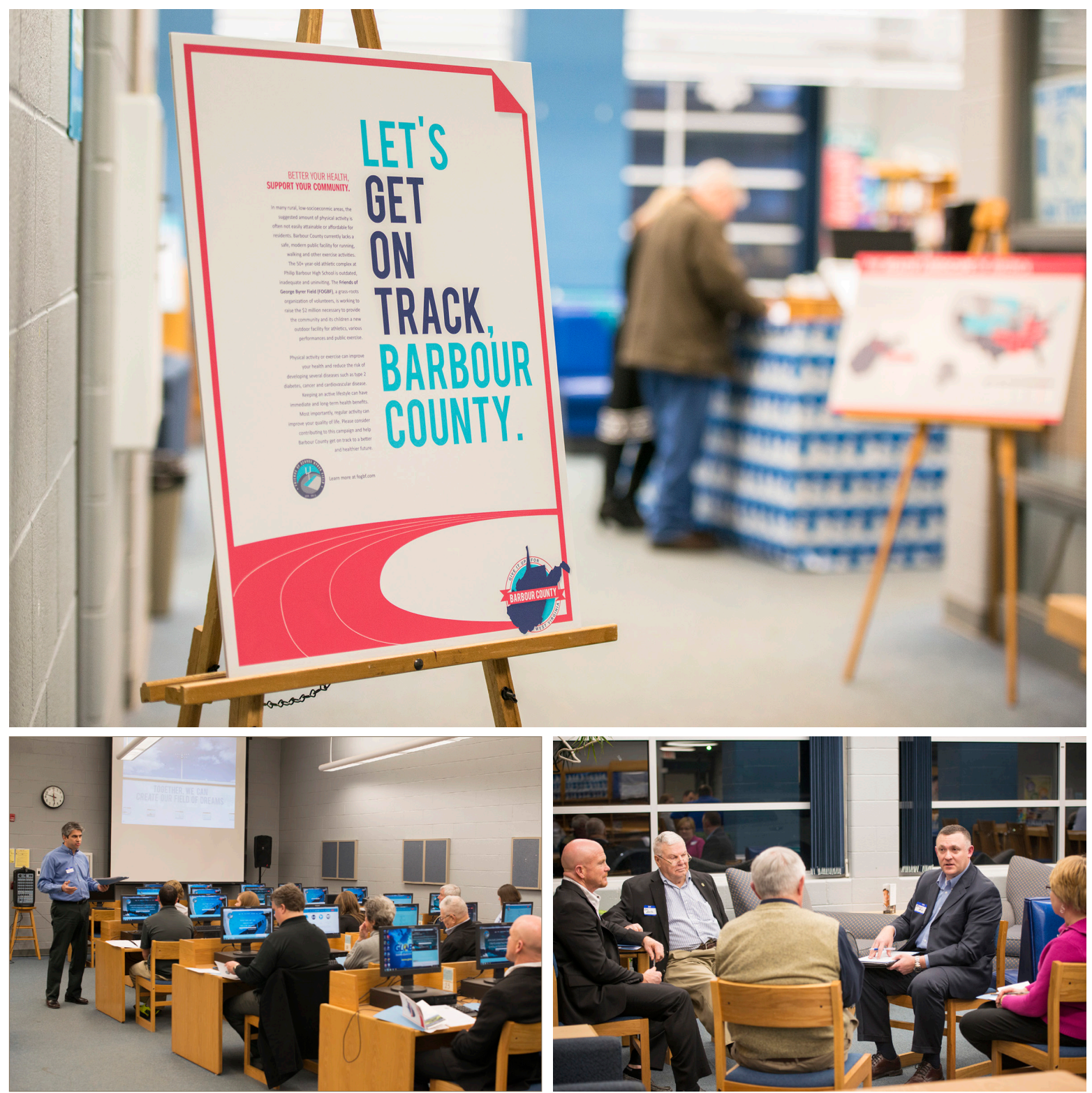

fig. (4.7) Collaborative community event held in the media center of Philip Barbour High School 


\section{THE HEALTH LANDSCAPE OF AMERICA}

For decades, studies and reports have regularly labeled the Mountain State as one of the unhealthiest in the USA. Unfortunately, West Virginia ranks near the very bottom in areas such as physical activity, smoking, obesity and diabetes. Barbour County, located in north central West Virginia, ranks in the bottom half, 34th of the 55 counties, in Virginia, ranks in the bottom half, 34 th of the 55 counties, overall health. With education, self-discipline and further
opportunities for physical activity, we can proudly make the heart of West Virginia healthier and stronger than ever
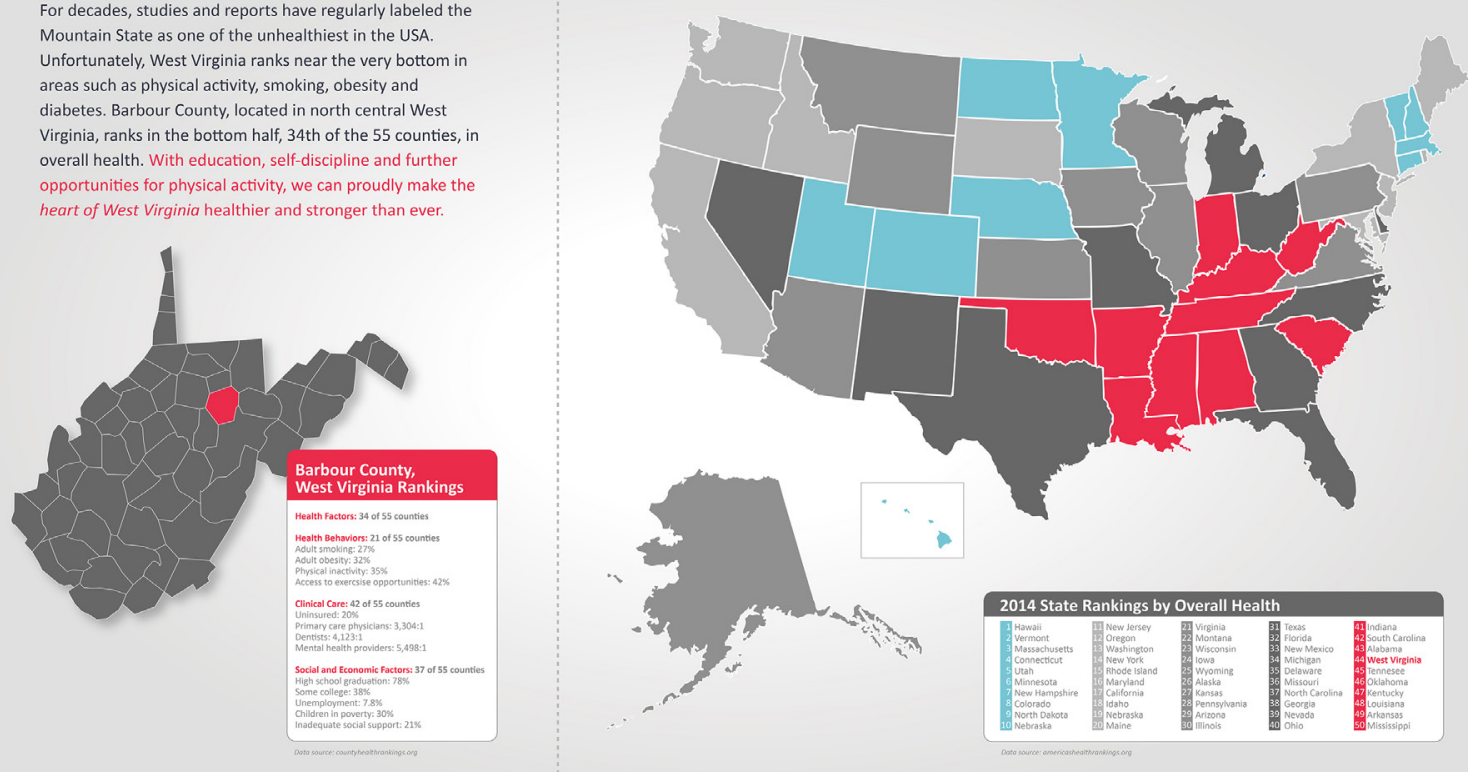

\section{BARBOUR COUNTY, WEST VIREINIA}

VS. SURROUNDING AREA

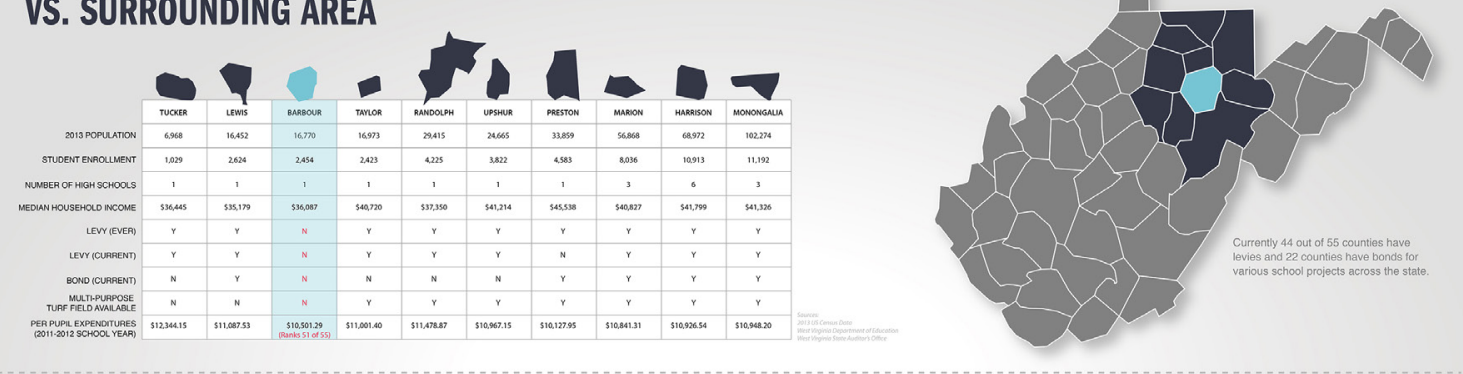

\section{BOND/LEVY ATTEMPTS}

Passed/Failed Bond and Levy Attempts (1960-Present)

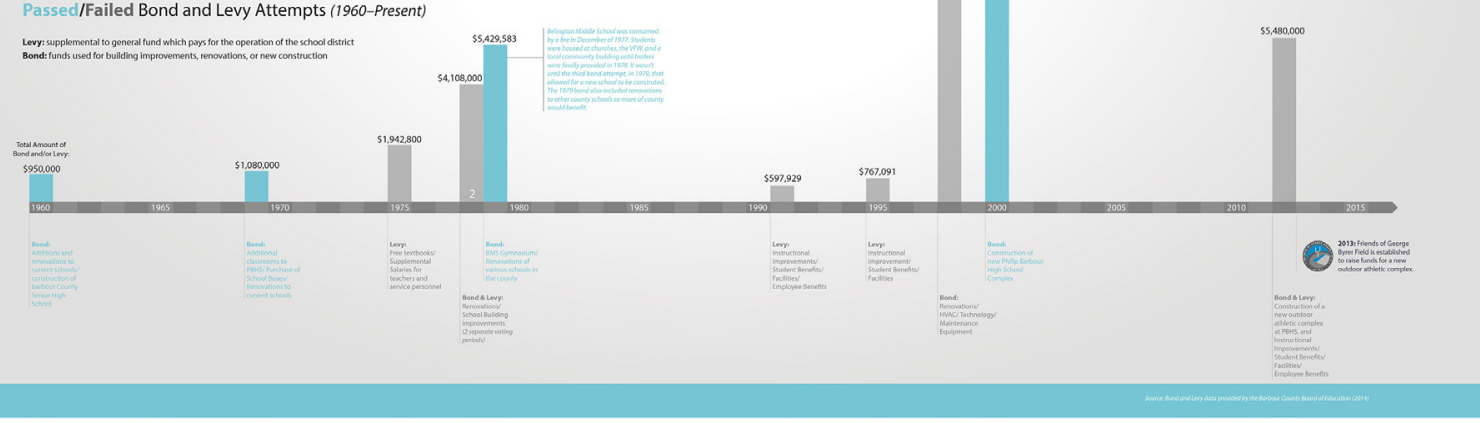

fig.(4.8) Data visualization posters displayed at community event as conversation starters 


\section{Chapter Five: Leveraging Local Resources}

The positive feedback from the event inspired a new approach to disseminating information and creating the opportunity for dialogue with the community. The FOGBF committee has strived to connect with established agencies, groups and organizations that by their mission or purpose already have a substantial interest in the welfare and progress of local citizens. In order to produce an extended and engaging reach into the community for this project, it was decided that the most practical approach would be to reach out to and team with those established groups and organizations that presently have a connection to the community through their common goals and objectives.

By pooling existing resources in the area, we are now able to implement a tactic that integrates seamlessly into the existing Barbour County structure. This strategy has the potential to empower the community to use a similar dissemination process in the future for a variety of issues and challenges. ${ }^{1}$

After deciding to target local organizations, I found it logical to create a similar framework for the content that drove the community collaboration event, so that the experience would be even more accessible to gatherings of various sizes. Using the Modes of Interaction model (Chapter 2), the focus remains on the group dynamic to maintain a fairly intimate experience, while simultaneously engaging an even larger percentage of stakeholders as compared to face-to-face interaction. This idea was my response to "taking the show on the road."

\section{Connecting with the Community}

I decided to create a prototype kit that could be easily transported in a box the size of a medium pizza, yet could contain all of the key components used during the community collaboration event. The sectioned container was designed to keep all materials neatly organized and easily accessible. The "program in a box" could be mailed to local groups to present the FOGBF initiative in a new and expanded way. Even better, committee members could take the kits for personal, in person presentations to PTOs, booster organizations, business leaders and county agency gatherings. The goal of the kit was to create a ripple effect of interest and support in the rural community, where small local groups are often the most influential. The kits include various materials to inform, educate, stimulate discussion, and require participation and response. Components within each kit ask members of the respective organization to do four things: Imagine, Advocate, Volunteer and Give.

1 Shea. Designing for Social Change, 97. 
The committee has produced a database of local organizations and prioritized that listing by their likelihood to participate and respond to the provided activities. This organized list has helped to inform the FOGBF on how to most efficiently distribute the kits. By reaching out to the groups in this personalized manner, the committee can show its project in a new and exciting way, and open lines of communication between our organization and theirs. The activities that require response naturally serve as a tool for creating dialogue. Not only does each recipient organization become educated and engaged, but individuals that make up the organization will be able to act as informed advocates for the FOGBF, discussing this project and its benefits with other individuals who may not be associated with any specific organization. This creates the desired ripple effect of messaging and information dissemination, offering more opportunities for dialogue and support surrounding this project. (fig. 5.1) By personally educating and engaging a larger audience (both groups and some individuals), the likelihood of gaining those residents' support is increased. With a better understanding of the project and its potential benefits for all demographics, residents will be more willing to imagine, advocate, give or volunteer for the cause.

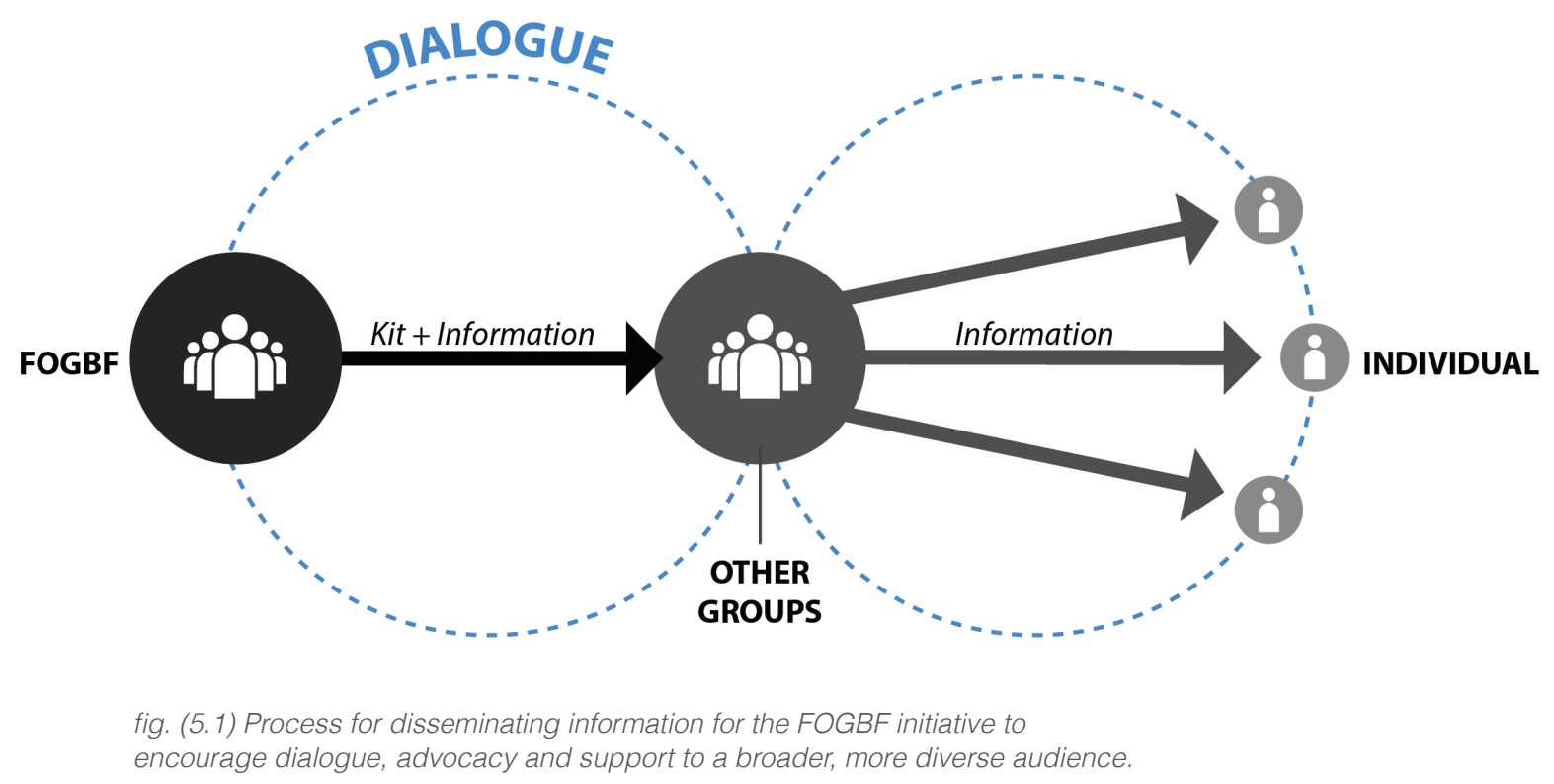




\section{Kit Components:}

(1) Kit Box

(4) Booklets

(4) Sketchbooks

(20) Individual Takeaway

(1) Disposable Camera, Directions

(2) Pre-paid Envelopes

\section{Kit Box}

The kit box is a 9"x9"x2" white packaging box, that has been screen printed to include the greeting: "Hello there, . We care about Barbour County, and we know you do, too!" A blank space after "Hello there," was included so that each box can be personalized to the specific group or organization it is being delivered to. The right half of the box lid was kept blank to leave room for mailing information. The concept of using a box that has a very specific, yet personalized message is meant to create a sense of wonder and excitement for the recipient. My goal was to make it feel like a gift or a treasure chest that the organization would be excited to open and explore the inner contents. Fifty of the kit boxes have been screen printed and are ready to be personalized and delivered to organizations as they are identified.

\section{Booklets}

The box is divided into four quadrants. The first quadrant consists of booklets that cover each of the four categories that the FOGBF wants to cover. The terms "Imagine, Advocate, Give, and Volunteer" were broken down into highly visual booklets that act as informational conversation pieces. These booklets include:

1. Imagine - "George Byrer Field: More than a Football Field"

2. Advocate - "We care about Barbour County, and we know you do, too"

3. Give - "Become a Friend of George Byrer Field, Today"

4. Volunteer - "Consider Investing in Your Community's Future"

The Imagine booklet specifically asks for participation from the organization pertaining to the idea of "thinking big" about the possibilities that exist within this project. Similar to the brainstorming activities held at the community event, the Imagine booklet replicates the exercises to allow organizations to explore ways to broaden the scope of the initiative from their perspectives. Two convenient self-addressed stamped envelopes are included in the kit to allow organizations to report back to the FOGBF with ease after completing the brainstorming activities located within the Imagine booklet. By eliminating the hassle of each receiver buying an envelope and a stamp, the likelihood of participation and response is increased. 
The Advocate booklet provides statistical data and research that solidify the needs as well as the potential benefits for this project. This reflects more in-depth information that can be shared and passed on to others that may have been absent during previous attempts to gain support for this initiative.

The Give booklet breaks down the project costs and also shows how manageable the fundraising process could be if everyone in the county contributed a little. According to the 2013 US Census, there are approximately 16,770 residents living in Barbour County. This $\$ 2,000,000$ project divided by the number of residents calculates to $\$ 0.33$ a day, $\$ 2.91$ a week, or $\$ 9.90$ a month for just one single year. Providing this breakdown of total cost (e.g. one order of fries per week for a year) makes \$2 million seem like a more attainable fundraising goal.

Finally, the Volunteer booklet focuses on providing organizations, along with the individuals that make up these groups, an opportunity to assist the FOGBF by providing their time, knowledge or resources. Clear and concise steps to follow, and contact sources if questions exist, make the package user friendly.

\section{Sketchbooks}

Four sketchbooks are provided for jotting down ideas, or creating drawings or plans, to help move along the brainstorming process. This is a repeated element from the community event, as it was determined to be beneficial in giving the participants a handy tool with which to record and remember discussion highlights, questions and important points during the discussion activities. 


\section{Camera: Participatory Element}

The camera activity is inspired by an initiative in Andrew Shea's book, Designing for Social Change. ${ }^{1}$ The goal of this component is to get residents to take a hard, objective look at their surroundings, including both the things that make them proud and the challenges that exist. This activity comes with a checklist of twelve photos to be taken with the provided disposable camera. Specifically, this phase asks the participant to stop by George Byrer Field and snap two photographs that are representative of the current physical state of the facility. The 12-exposure disposable camera is to be mailed back to or dropped off at the Barbour County Board of Education or to a FOGBF committee member. At that point, the organization will have the photos developed and add them to the collection of photos on the FOGBF's Facebook page. The outcome will be the creation of a visual library that is open to the public, one that showcases the different perspectives of various groups, organizations and individuals. As it grows, the library will act as a vehicle for discussion and commentary on bettering Barbour County, beginning with this initiative.

\section{Individual Pamphlet}

Twenty individual takeaways are provided in the kit for individuals within the organization to keep following the meeting to share with others. This step will help in the dissemination of information from group to individual, creating yet a further reach into the community. By presenting these takeaways, the organization also provides a physical reminder to the group members. The takeaway for the FOGBF kit is a four-page pamphlet that explores the basic costs associated with the project, and how individuals in the community can formulate a plan to contribute financially to the cause. Again, I chose to include the breakdown of costs for the new complex, divided by the number of residents in Barbour County. The concept is that if every individual living in the county were to give an equal share of financial support to the effort, the $\$ 2,000,000$ goal would suddenly seem more manageable. 


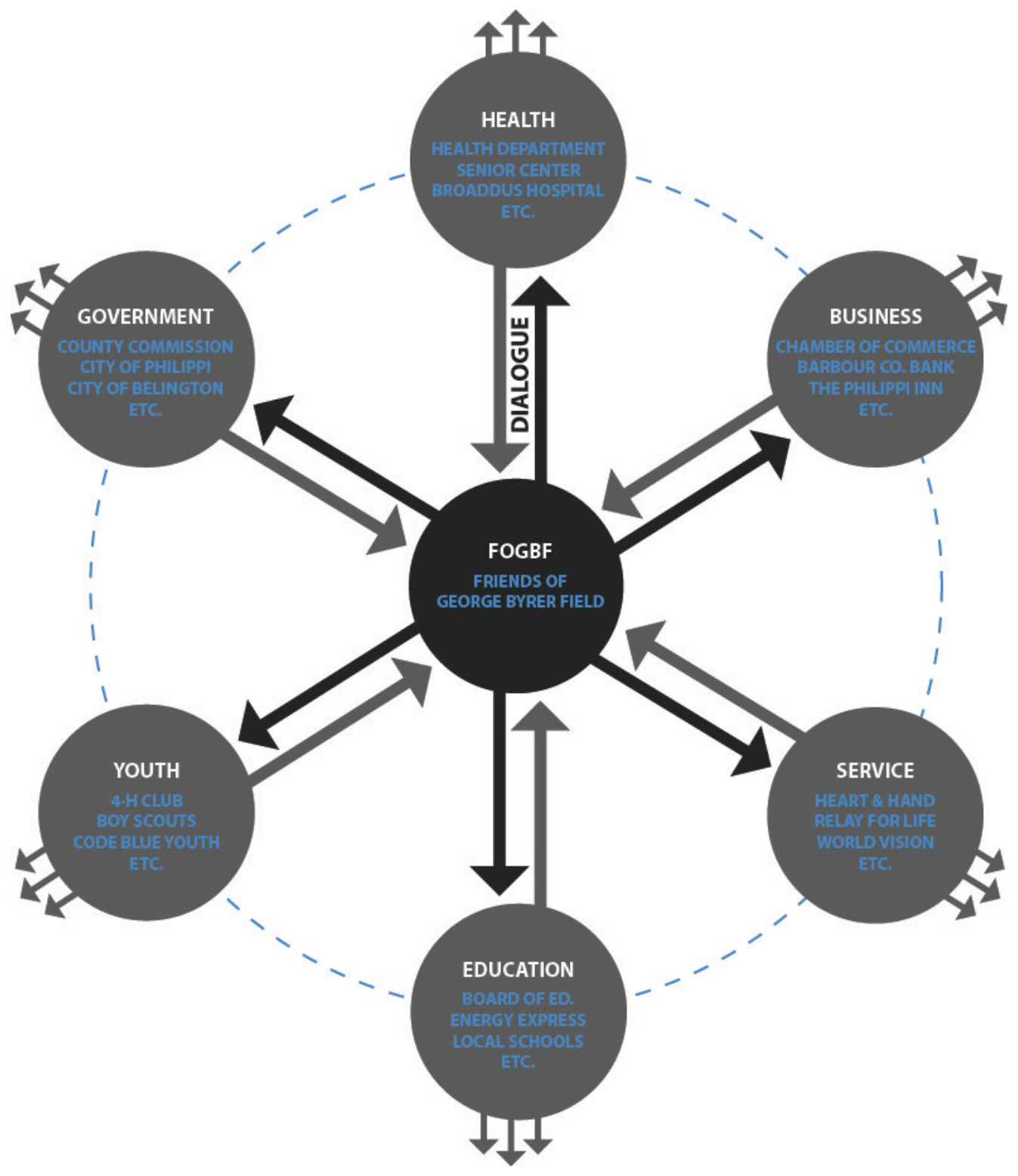

\section{THE WHEEL OF STAKEHOLDER INTERACTION}

Fig. (5.2) This map serves as an example of the information dissemination and interaction process used within the FOGBF initiative. In order to leverage local resources and increase community support, the "group" mode of interaction was defined as the main target. Whereas the project was initially defined as the main beneficiaries being the youth of the county, the entirety of potential beneficiaries was divided into six categories: Health, Business, Service, Education, Youth and Government. In this map, the FOGBF acts as the hub while all of the possible relationships that exist with local organizations act as the tread of the wheel. It could be said that this is "where the rubber meets the road" because of its critical nature. The opportunities for dialogue are represented by the arrows portrayed as the spokes of the wheel, creating a strong relationship between the central hub and outer tread. In the instance of this case study, the FOGBF reached out to stakeholder organizations by: first, a community collaboration event which encouraged them to come to us and then, secondly, a participatory kit which allowed the FOGBF to "visit" target organizations through provided boxes full of pertinent information and group activities. With all of these elements working in tandem, a network of caring individuals and organizations is provided with the basic tools that will equip each with the knowledge and skills to act as advocates for this project, giving it more traction as it progresses and expands. This can consequently create a ripple effect throughout the community as outer organizational members can further share their new knowledge and engage effectively in dialogue about this project. 


\section{Moving Forward}

After generating new excitement around the initiative and offering opportunities for area residents to engage in meaningful dialogue, it will be important to keep those individuals interested and involved. The brainstorming activities from the community event and kit resulted in a wealth of new ideas for engaging a larger percentage of the community once the new facility is completed and opened to the public. To stay motivated and keep traction, those ideas need to be transferred into participatory opportunities for the stakeholders, so that they feel a sense of engagement and ownership in this project. In this situation, the goal is to reach a broader audience by being intentional and, consequently, more effective in the information dissemination process. Especially in low-socioeconomic areas like Barbour County, residents may not be able to support the cause financially but, by giving them an alternative means with which to express their support, they may be more motivated to contribute in some other tangible way.

Perhaps testing some of these events at the current facility would not only help residents imagine the possibilities at a state-of-the-art facility, but they could offer additional fundraising opportunities that can get the FOGBF even closer to their financial goals while building a closer-knit community. As examples, this could be conducted by starting summer recreational leagues for adults, hosting a community yard sale around the old running track, where proceeds are donated to the initiative, or even planning a community Family Day full of fun activities, games and music for all to enjoy. Transferring future ideas into today's real-life events at the current George Byrer Field could generate interest and help residents support the cause while having fun with their neighbors.

There are effective, existing resources available for guiding action after the collection of information and ideas from the brainstorming activities. Frog Design and IDEO each have free, downloadable toolkits that include activities and methods created to enable groups of people anywhere to organize, collaborate, and create solutions for problems that impact their communities. The goal of the Frog Collective Action Toolkit is to help communities generate solutions, connect to resources, and pool knowledge to help solve a wide range of challenges and create real change. ${ }^{1}$ IDEO's Human-Centered Design Toolkit, meanwhile, can transform data into actionable ideas, assist in allowing users to see new opportunities and increase the speed and effectiveness of creating new solutions. ${ }^{2}$ These toolkits are proven collections of instruments that can make a real difference in transforming ideas into positive action.

1 Frog Collective Action Toolkit, Frog Design, Accessed April 29, 2015, http://www.frogdesign.com/work/frog-collective-action-toolkit.html

2 Human-Centered Design Toolkit, IDEO, 2009, PDF e-book. 

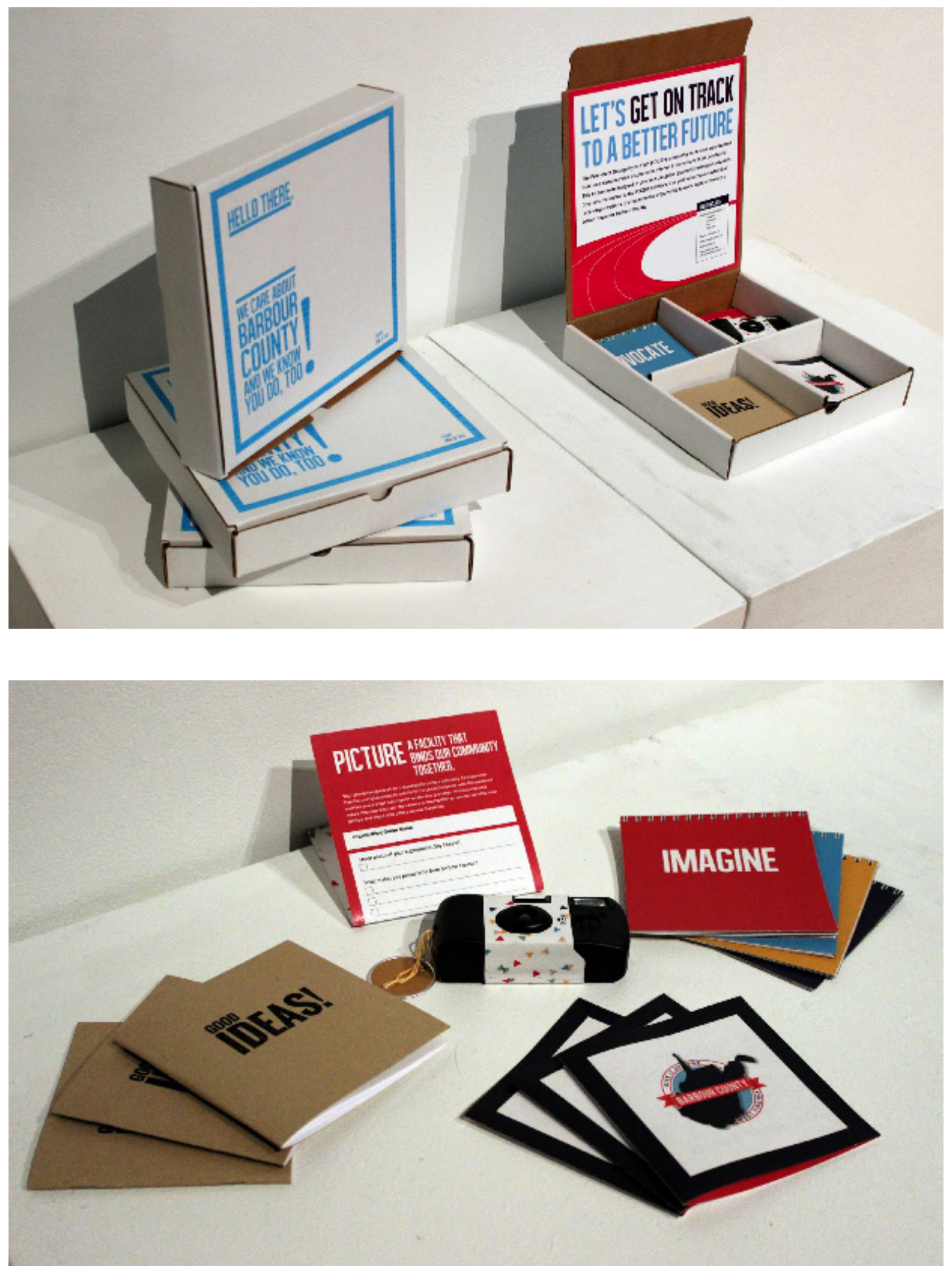

fig.(5.3) Kit box and components 


\section{Public Exhibition}

On April 2, 2015, I was provided an opportunity to display my thesis work in the Laura Mesaros Gallery at the Creative Arts Center of West Virginia University. Using the case study project described in this project, I used my research and methodology to educate dozens of visitors about the uniques role that design can play in creating social change. The gallery was open to the general public, so it was important for me, as the designer, to display the work and process in a manner that would allow for easy interpretation and understanding by the viewers. I divided my research and design implementation process into six main steps which led to the development of a kit, each represented by a poster displayed on the gallery wall. Because the gallery is set up in a counter-clockwise fashion, I used large numbers within the poster layout to help guide the visitors through the space in linear manner, step by step, leading to the culmination of my research, the engaging kit to be shared with organizations across and around Barbour County.

As a primary focal point, photos taken at the January 29th community event were projected on the entire back wall of the gallery space. These photographs showed the FOGBF organization engaging residents in communication and brainstorming activities surrounding the initiative. The placement and size of the projection was meant to pique interest and draw viewers into the gallery.

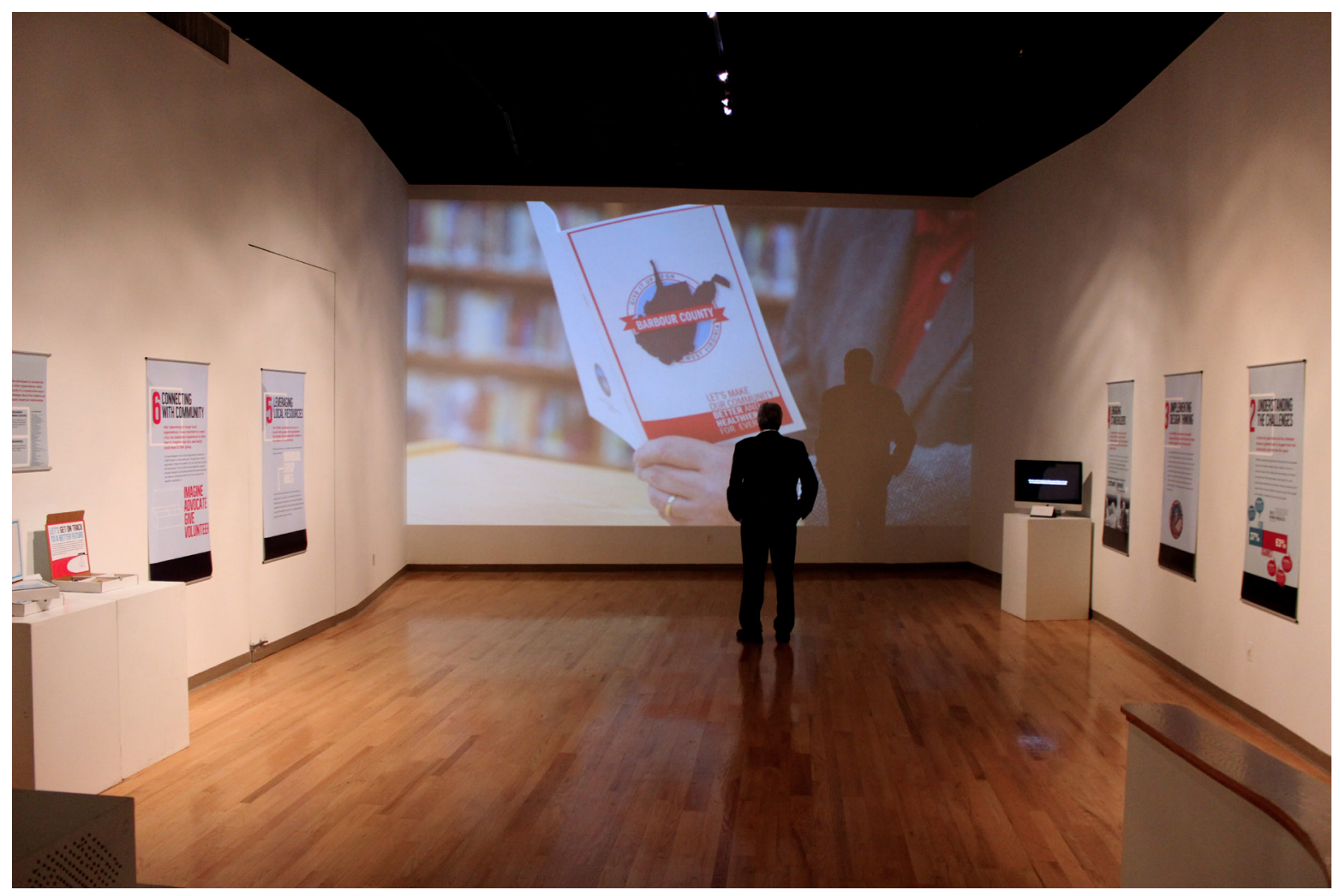

fig.(6.1) Gallery space for Lauren Schiefelbein's MFA exhibition 
Additionally, a looping video was displayed on a computer that featured B-roll footage of the facility, which I had taken with a Canon t3i DSLR camera during the fall months of 2014. The video opens with a scene of two high school teams battling it out on George Byrer Field in front of a large, cheering crowd. The B-roll presentation was pieced together in an effort to allow visitors to the gallery to empathize with those who have no choice but to accept the current conditions of the facility. The different shots that I chose to include in the video component truly demonstrate the need for a new facility; for example: a rainsaturated football field, a coach attempting to paint yard lines onto the muddy surface, and a cinder track overtaken by grass and weeds. The 50+ years of "wear and tear" are obvious and the video component was useful in clearly depicting the problems that Barbour County faces.
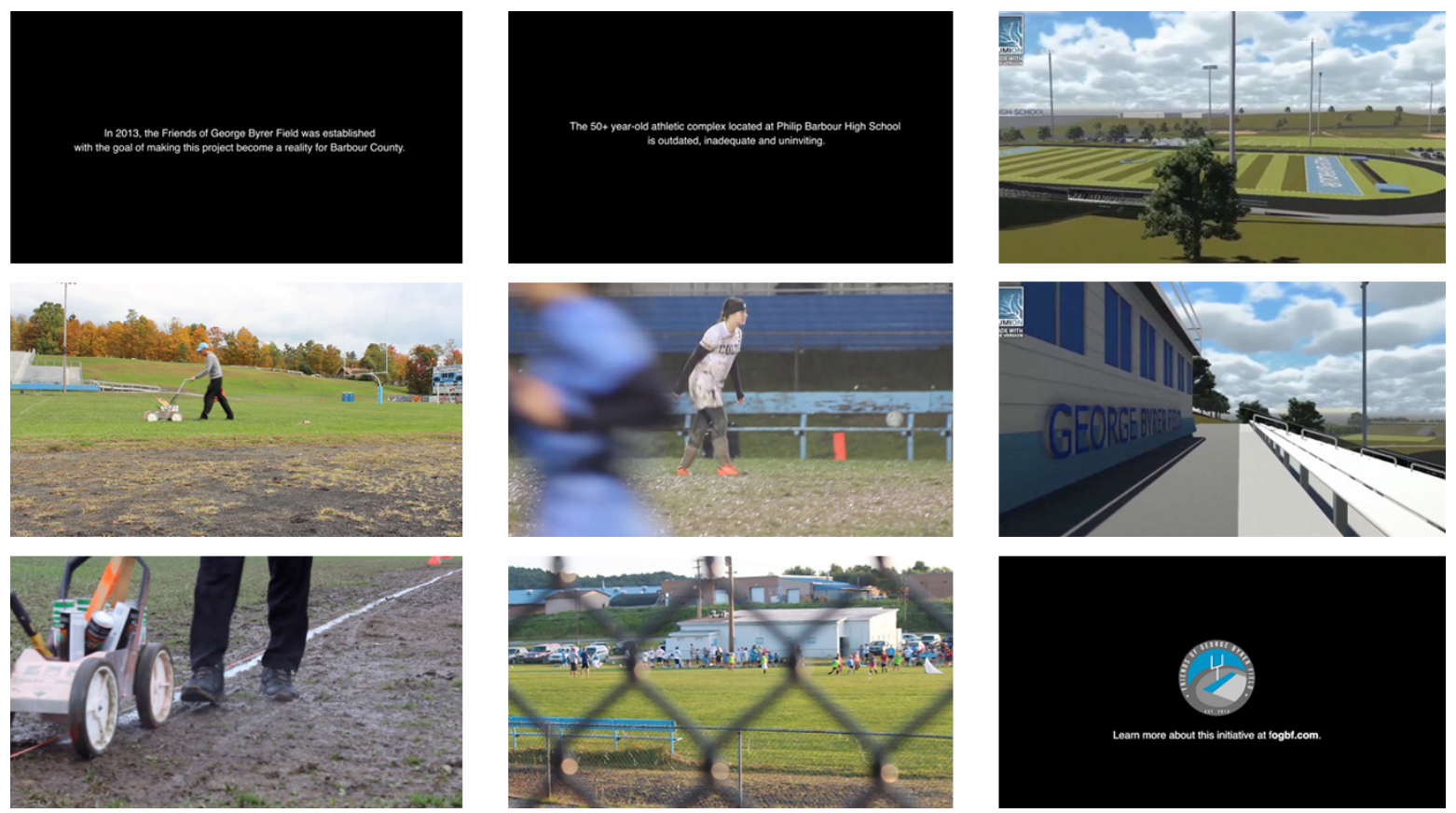

fig.(6.2) Stills from video component in MFA exhibition 


\section{Script for video component:}

George Byrer Field Barbour County, WV

The 50+ year-old athletic complex located at Philip Barbour High School is outdated, inadequate and uninviting.

Barbour County School proposed a school bond to provide the necessary funding for a new facility on two separate occasions.

Both attempts were voted down by Barbour County residents.

In 2013, the Friends of George Byrer Field was established with the goal of making this project become a reality for Barbour County.

Not only would the facility benefit the youth of Barbour County, but it would touch the lives of all residents for years to come.

Imagine a performance, athletic and fitness facility for our entire community to enjoy and be proud of.

Learn more about this initiative at fogbf.com. 
In fact, some residents in the community were unaware of the existing conditions and, by providing this video in a public space, I allowed residents to better understand why this new facility is so badly needed. Contrasting the opening scenes of the video, a digital rendering of the proposed new facility reveals the plans for the new athletic and performance park. The 3-D rendering helped viewers to imagine the new state-of-the-art grounds and structures, and what it would mean to the youth and entire community. The strategy involved combining scenes that first evoke empathy, and then shift viewers to imagining a better future for the community and its children, with the goal of winning each individual's support for the venture.

Below are copies of the exhibition posters and text copy that helped to guide visitors through my research process and design decisions.

CASE STUDY:

\section{BARBOUR COUNTY, WEST VIRGINIA}

Barbour County, like many other once-thriving rural communities throughout the United States, finds itself in a struggle to maintain a sense of identity due to demographic shifts that have occurred over time.

Without a steady economy and strong local resources, small town America faces a growing number of barriers in its efforts to stay relevant. When friendliness, charm, open spaces and a slower pace of living are not enough, rural areas are faced with the challenges of lands, and a population of 16,770 residents. While it is blessed with natura beauty and good people, it is a chronically low socio-economic county in one of the unhealthiest states of the United States. Once an important part of a booming coal region, Barbour County has never fully recovered economically from the industry's exodus in the late 1970's and 1980's.

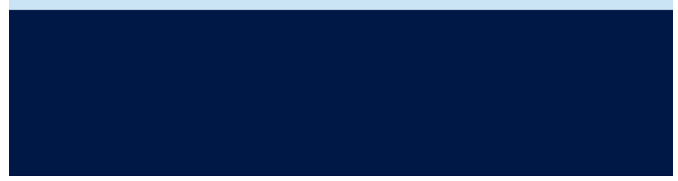

fig.(6.3) Case Study poster from MFA exhibition

\section{Case Study: Barbour County, West Virginia} Barbour County, like many other once-thriving rural communities throughout the United States, finds itself in a struggle to maintain a sense of identity due to demographic shifts that have occurred over time. Without a steady economy and strong local resources, small town America faces a growing number of barriers in its efforts to stay relevant. When friendliness, charm, open spaces and a slower pace of living are not enough, rural areas are faced with the challenges of making their communities more desirable places to live. Barbour County is comprised of several small rural communities, alternately wooded and open lands, and a population of 16,770 residents. While it is blessed with natural beauty and good people, it is a chronically low socioeconomic county in one of the most unhealthy states of the United States. Once an important part of a booming coal region, Barbour County has never fully recovered economically from the industry's exodus in the late 1970's and 1980's. 

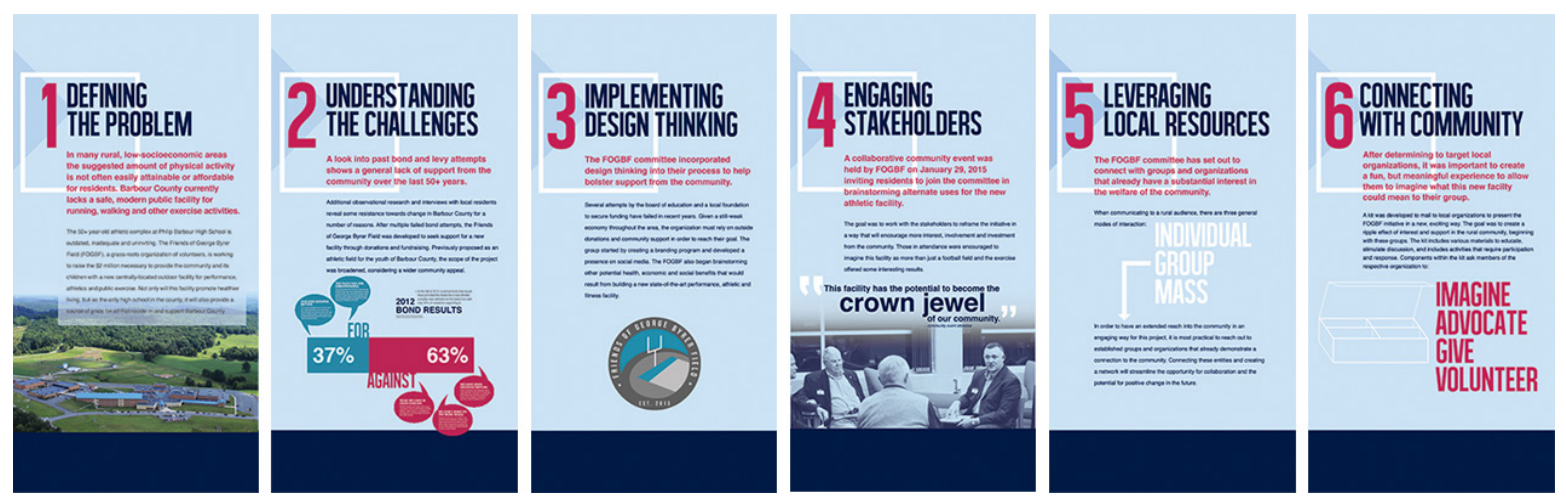

\section{Defining the Problem}

In many rural, low-socioeconomic areas the suggested amount of physical activity is not often easily attainable or affordable for residents. Barbour County currently lacks a safe, modern public facility for running, walking and other exercise activities. The 50+ year-old athletic complex at Philip Barbour High School is outdated, inadequate and uninviting. The Friends of George Byrer Field (FOGBF), a grassroots organization of volunteers, is working to raise the $\$ 2$ million necessary to provide the community and its children with a new centrally-located outdoor facility for performance, athletics and public exercise. Not only will this facility promote healthier living, but as the only high school in the county, it will also provide a source of pride for all that reside in and support Barbour County.

\section{Understanding the Challenges}

A look into past bond and levy attempts shows a general lack of support from the community over the last 50+ years. Additional observational research and interviews with local residents reveal some resistance towards change in Barbour County for a number of reasons. After multiple failed bond attempts, the Friends of George Byrer Field was developed to seek support for a new facility through donations and fundraising. Previously proposed as an athletic field for the youth of Barbour County, the scope of the project was broadened, considering a wider community appeal.

\section{Implementing Design Thinking}

The FOGBF committee incorporated design thinking into their process to help bolster support from the community. Several attempts by the board of education and a local foundation to secure funding have failed in recent years. Given a still-weak economy throughout the area, the organization must rely on outside donations and community support in order to reach their goal. The group started by creating a branding program and developed a presence on social media. The FOGBF also began brainstorming other potential health, economic and social benefits that would result from building a new stateof-the-art performance, athletic and fitness facility. 


\section{Engaging Stakeholders}

A collaborative community event was held by FOGBF on January 29, 2015 inviting residents to join the committee in brainstorming alternate uses for the new athletic facility. The goal was to work with the stakeholders to reframe the initiative in a way that will encourage more interest, involvement and investment from the community. Those in attendance were encouraged to imagine this facility as more than just a football field and the exercise offered some interesting results.

\section{Leveraging Local Resources}

The FOGBF committee has set out to connect with groups and organizations that already have a substantial interest in the welfare of the community. When communicating to a rural audience, there are three general modes of interaction: individual, group and mass. In order to have an extended reach into the community in an engaging way for this project, it is most practical to reach out to established groups and organizations that already demonstrate a connection to the community. Connecting these entities and creating a network will streamline the opportunity for collaboration and the potential for positive change in the future.

\section{Connecting with Community}

After determining to target local organizations, it was important to create a fun, but meaningful experience to allow them to imagine what this new facility could mean to their group. A kit was developed to mail to local organizations to present the FOGBF initiative in a new, exciting way. The goal was to create a ripple effect of interest and support in the rural community, beginning with these groups. The kit includes various materials to educate, stimulate discussion and includes activities that require participation and response. Components within the kit ask members of the respective organization to: Imagine, Advocate, Give and Volunteer.

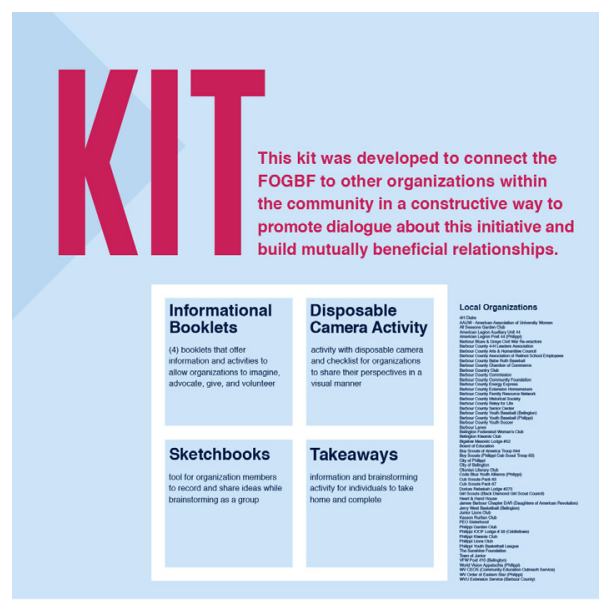

\section{Kit for Organizations}

This kit was developed to connect the FOGBF to other organizations within the community in a constructive way to promote dialogue about this initiative and build mutually beneficial relationships.

fig.(6.5) Data visualization posters displayed at community event as conversation starters 

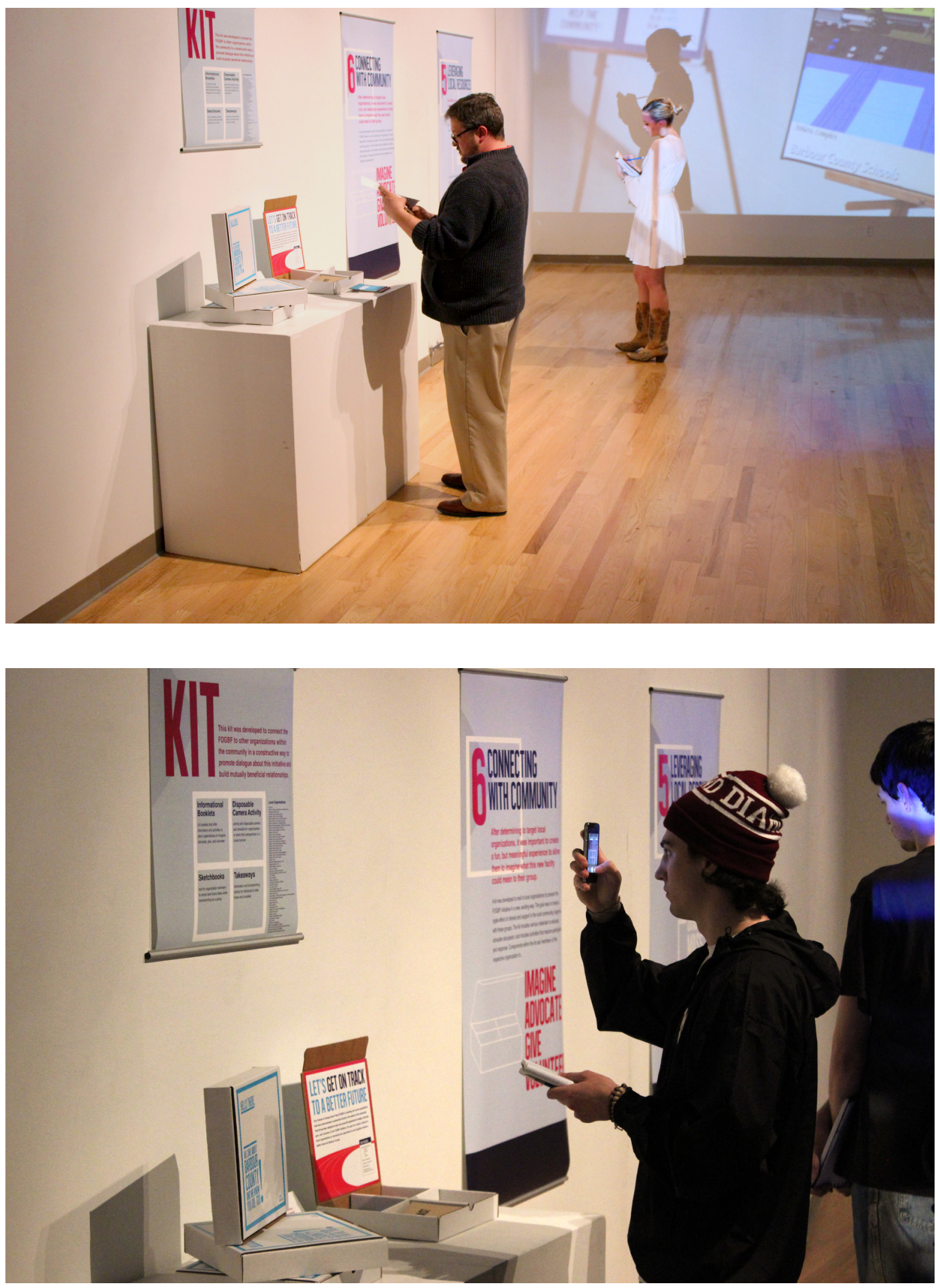

fig.(6.6) Visitors exploring the gallery space 


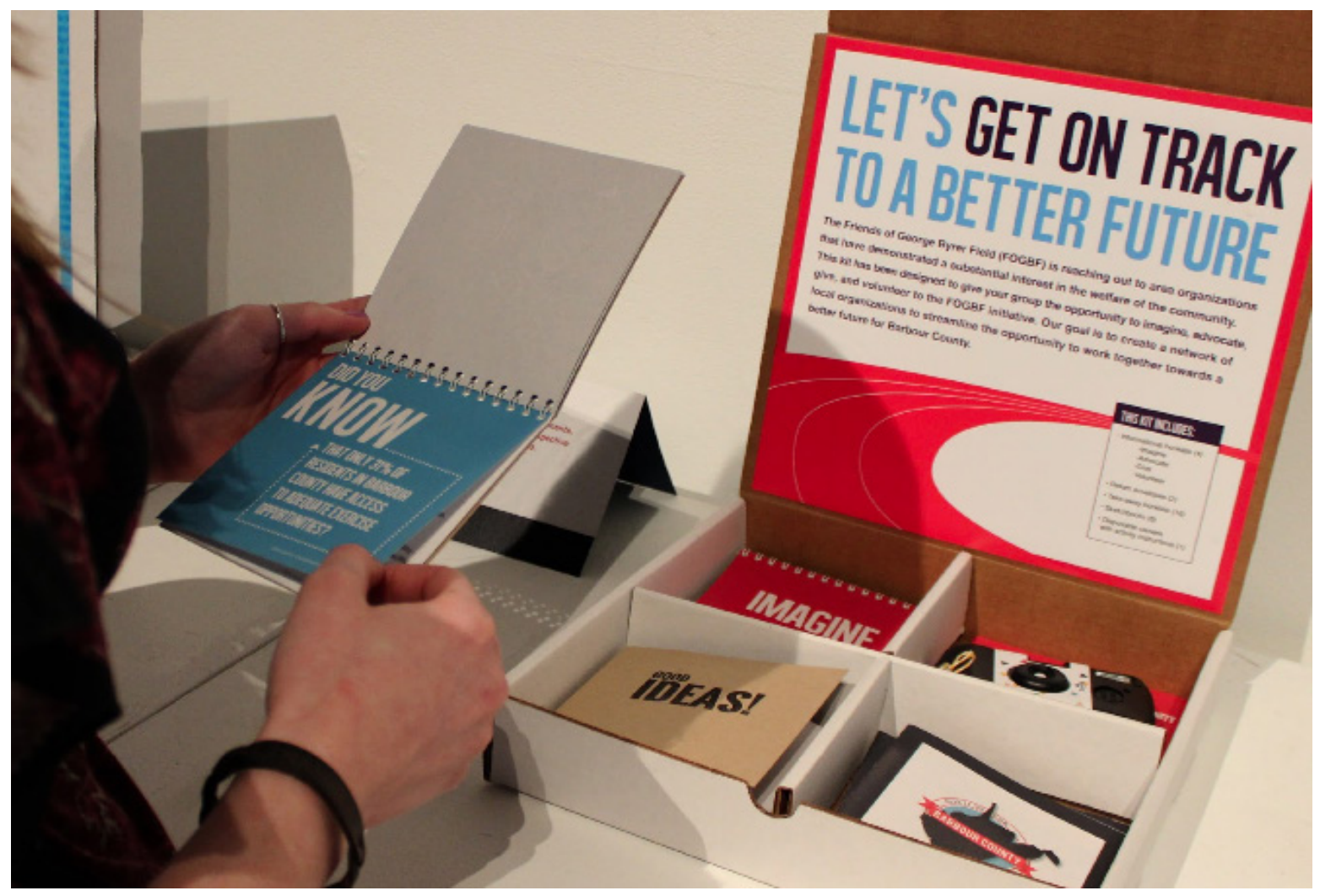

fig.(6.7) Kit and Advocate booklet

\section{Reflection on Public Exhibition}

My MFA thesis exhibition acted as an educational experience for both designers and nondesigners to learn and understand the role that design thinking can play in initiating change for rural communities. Placing my research into the context of a real-world challenge helped the audience see design thinking in action, and the type of the results that follow.

As visitors explored the gallery space, I noticed that many of them seemed to be intrigued by the video component that displayed scenes of George Byrer field as it exists today versus the digital rendering of what the new "field of dreams" would someday offer residents. This presentation in pictures shared a compelling narrative of the past, present and future, allowing viewers to empathize with Barbour County residents. Plans have been made by the Friends of George Byrer Field to implement this video component further by including a jumpdrive copy of the program into the organization's kit. 


\section{Conclusion}

Working with rural communities presents challenges that designers must consider and address in order to help facilitate positive change for local residents. Throughout the process of gathering research, I found residents to be hesitant in supporting a project that, to them, is so costly, and seemingly would only affect a small portion of the area population, the kids. The original focus for the project was to highlight its benefits for the youth of Barbour County, although the main topic of conversation usually turned to the financial burden. The additional emphases of potential health, economic and social benefits that would follow completion of such a new state-of-the-art facility had never before played a serious role in the conversation. After being dismissed on four earlier occasions, this project had lost its steam. Discouragement had settled in for those who supported the construction of a new complex, and it was just accepted that Barbour County would never see a performance, athletic and fitness facility of which to be proud. But, with the dedication of the Friends of George Byrer Field, and the infusion of design thinking into its strategy, the project has gained new life and is changing the ways that residents view, understand and speak about the project.

The goal of the FOGBF test tube case study was to create a viable and adaptable process for both this and future initiatives in Barbour County, but also for other rural communities that face similar challenges in reaching and engaging stakeholders to gain support for important local initiatives. An honest change of attitudes and communication patterns in rural communities tends to be a lengthy process that occurs only after prior negative experiences are replaced by new forms of interaction that give the community valid reasons to think and feel differently, allowing citizens to take a fresh new look at the issues that affect them. It is important to note that within the same community, different groups of stakeholders will find themselves to be at different stages in their support or advocacy of an initiative. These groups will require different design strategies and channels of communication from the established modes of interaction to effectively communicate and engage each segment. Creating social change in rural communities can present many unique challenges, but design and design thinking has the power to act as a catalyst in empowering them to find smart, sustainable solutions as they strive to build better lives for their citizens both today and tomorrow. 


\section{Bibliography}

County Health Rankings \& Roadmap: 2015. "West Virginia Health Factors.” Accessed January 18, 2015. http://www.countyhealthrankings.org.

Frog Design, "Frog Collective Action Toolkit." Accessed April 29, 2015. http://www.frogdesign.com/work/frog-collective-action-toolkit.html

Glaser, Milton, and Jonathan Barnbrook. "Milton Glaser and Jonathan Barnbrook Discuss Design's Rules of Engagement." Creative Review 23, no. 5 (December 2003): 52-56. Art Abstracts (H.W. Wilson), EBSCOhost (Accessed November 16, 2014).

IDEO, Human-Centered Design Toolkit, 2009. PDF e-book.

Local News 8. "School Levy or Bond: What's the Difference" Last modified March 12, 2013. http://www.localnews8.com/news/School-levy-or-bond-What-s-the-difference/19231400.

Maibach, Edward. Designing Health Messages: Approaches from Theory and Public Health Practice. Sage Publications, Inc., 1995.

Pilloton, Emily. Design Revolution: 100 Products That Empower People. New York: Metropolis Books, 2009.

Project M. "Project M." Accessed April 6, 2015. http://www.projectmlab.com/Project-M.

Severson, Kim. "Digital Age Is Slow to Arrive in Rural America." New York Times, February 2011. Accessed March 11, 2015. http://www.nytimes.com/2011/02/18/us/18broadband.html.

Shea, Andrew. Designing for Social Change. New York: Princeton Architectural Press, 2012.

Siegel, Michael and Lynne Doner. Marketing Public Health, Strategies to Promote Social Change. Jones \& Bartlett Learning, 2006.

The Design Observer Group, "Designing for Social Change.” Accessed February 18, 2015, http://designobserver.com/feature/designing-for-social-change/33188.

The Design Observer Group," Pizza Farm.” Accessed April 13, 2015. http://designobserver.com/feature/pizza-farm/10597.

Tischler, Linda. “IDEO’s David Kelley on Design Thinking.” Fast Company, February 2009.

Accessed April 16, 2015. http://www.fastcompany.com/1139331/ideos-david-kelley-design-thinking.

United States Department of Agriculture Economic Research Service. "Rural America at a Glance, 2014

Edition." Accessed April 6, 2015. http://www.ers.usda.gov/publications/eb-economic-brief/eb26.aspx. 